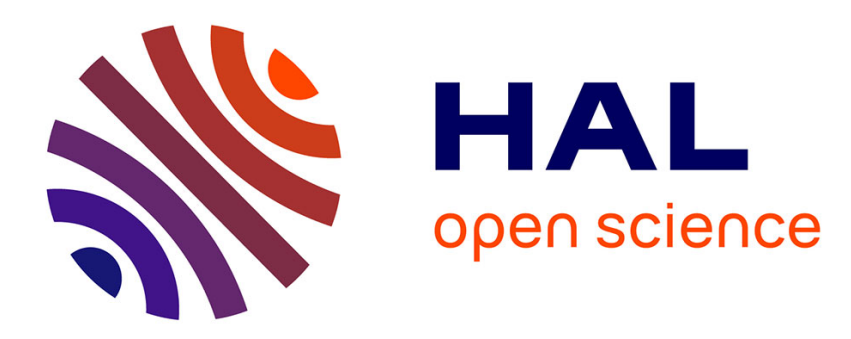

\title{
Complete analytical model of a loop heat pipe with a flat evaporator
}

B. Siedel, V. Sartre, F. Lefèvre

\section{To cite this version:}

B. Siedel, V. Sartre, F. Lefèvre. Complete analytical model of a loop heat pipe with a flat evaporator. International Journal of Thermal Sciences, 2015, 89, pp.372-386. 10.1016/j.ijthermalsci.2014.11.014 . hal-01286580

\author{
HAL Id: hal-01286580 \\ https://hal.science/hal-01286580
}

Submitted on 11 Mar 2016

HAL is a multi-disciplinary open access archive for the deposit and dissemination of scientific research documents, whether they are published or not. The documents may come from teaching and research institutions in France or abroad, or from public or private research centers.
L'archive ouverte pluridisciplinaire HAL, est destinée au dépôt et à la diffusion de documents scientifiques de niveau recherche, publiés ou non, émanant des établissements d'enseignement et de recherche français ou étrangers, des laboratoires publics ou privés. 


\title{
Complete analytical model of a loop heat pipe with a flat evaporator
}

\author{
Benjamin Siedel, Valérie Sartre*, Frédéric Lefèvre \\ Université de Lyon, CNRS \\ INSA-Lyon, CETHIL UMR5008, F-69621, Villeurbanne, France \\ Université Lyon 1, F-69622, Villeurbanne, France
}

\begin{abstract}
A steady-state analytical model has been developed to determine the thermohydraulic behaviour of a loop heat pipe with a flat evaporator. Its main originality lies in the combination of energy balance equations for each component of the system with 2D analytical solutions for the temperature field in the evaporator. Based on Fourier series expansion, heat transfer in the wick as well as in the evaporator casing are accurately modelled, enabling a thorough consideration of the parasitic heat fluxes. The model is based on the thermal contact resistance between the wick and the casing, the thermal conductivity of the wick and the accommodation coefficient. This analytical method offers a simple solution that can be implemented in LHP design analysis without the need of large computational resources. A sensitivity analysis has been carried out to evaluate the influence of several parameters on the LHP behaviour. The results show that the main parameters of the model are independent. Therefore, they could be experimentally determined using an appropriate test bench with only few temperature measurements. The model has been validated with a set of experimental data from the literature. A good agreement is found between the theoretical and the experimental results.
\end{abstract}

Keywords: Loop Heat Pipe, Analytical, Modeling, Sensitivity analysis

\section{Introduction}

Loop Heat Pipes (LHP) are two-phase cooling systems able to passively transport high amounts of heat over distances up to several meters. Developed in the 1970's, these devices have proven their reliability in many spatial applications and are now candidates for terrestrial cooling solutions. Indeed, their specific design offers robustness and flexibility for a wide variety of practical applications [1, 2].

As a consequence, many efforts have been dedicated to understand their operation in order to optimize their design. A LHP is a complex thermal system including an evaporator connected to the heat source, a condenser to dissipate the heat load and vapour and liquid lines to transport the working fluid between both components. Coupled thermo-hydraulic phenomena govern the LHP behaviour and need to be understood to enable a correct system designing. Parameters such as evaporation efficiency, heat losses to the ambient and parasitic heat flux in the evaporator as well as condensation heat transfer can be of great influence on the loop operation.

A lot of papers concerning LHP complete modelling can be found in the literature [3-6]. However, these numerical models often imply complex algorithms and large computational resources which are not always available for upstream pre-design applications. An analytical model offers

\footnotetext{
* Corresponding author

Email address: valerie.sartre@insa-lyon.fr (Valérie Sartre)
}

the advantage to provide a solution without an excessive computing time and that can be easily implemented. Some analytical models of LHP are found in research works. Maydanik et al.[7] (cited by Launay et al.[8]) suggested a closed form solution of a LHP analytical model establishing the energy balance in the reservoir and the pressure balance in the whole system. Furukawa[9] developed a complete analytical model of a LHP able to enhance the sizing of the system and to study the influence of many geometrical parameters on the loop operation. However, the model requires the operating temperature as input parameter. Yet in most cases, the evaporator temperature is the main expected output of a LHP model. Launay et al. [8] proposed closed-form expressions of the operating temperature of the LHP, for both the variable and the fixed conductance mode. Their model is based on energy balance equations on each system component and on thermodynamic equations. The thermal links in the reservoir are defined as equivalent thermal resistances. Their solution is a useful tool in the LHP design. However, the heat transfer in the evaporator is not accurately determined and has to be adjusted in accordance with experimental data. The purpose of the present study is to present a complete analytical model of a Loop Heat Pipe accurately taking into account heat and mass transfer in the evaporator structure. The model is developed for a flat disk-shaped evaporator geometry. This model is based on the analytical study of Launay et al.[8]. However, the present study rests upon two 2-D analytical solutions describing the tem- 
perature field in the wick and the evaporator casing. Both solutions enable to determine parasitic heat losses through the wick and the evaporator body, the sensible heat given to the liquid flowing through the porous structure as well as the heat dissipated by evaporation at the wick-groove interface. A similar approach was implemented in the case of conventional heat pipes by Lefèvre and Lallemand [10] and later extended by Lips and Lefèvre [11]. These features, coupled with energy balances and thermodynamic relationships in the rest of the LHP, give a simple solution for the operating temperature. An iterative procedure is implemented to calculate the two-phase length in the condenser.

\section{Model description}

\subsection{Analytical Model of the LHP}

The thermal state of the complete LHP can be determined using energy balance equations and thermodynamic relationships. Figure 1 presents the operating principle of the LHP and the links between its components.

The total heat load to be dissipated by the evaporator $Q_{\text {in }}$ is conducted through the wick or through the evaporator body so that:

$$
Q_{\text {in }}=Q_{\mathrm{w}}+Q_{\mathrm{b}}
$$

The wick is assumed to be fully saturated with liquid. The thermal heat flux $Q_{\mathrm{w}}$ is transversally conducted through the evaporator wall, the wall-wick interface and then divides up: a part $Q_{\mathrm{ev}}$ is evaporated at the wick-groove interface whereas the rest is dissipated by conduction and convection with the liquid flowing through the porous structure and with the liquid in the reservoir. $Q_{\mathrm{b}}$ is conducted longitudinally through the evaporator wall to the reservoir and a part of it, $Q_{\text {ext,e }}$, is given by convection to the ambient. Both the heat flux through the wick $Q_{\mathrm{w}}$ and the heat flux conducted through the evaporator casing $Q_{\mathrm{b}}$ are functions of the reservoir, the groove, the wick and the evaporator temperatures $T_{\mathrm{r}}, T_{\mathrm{v}}, T_{\mathrm{we}}$ and $T_{\mathrm{e}}$. The same dependence applies for $Q_{\mathrm{ev}}$ and $Q_{\mathrm{ext}, \mathrm{e}}$ :

$$
\begin{aligned}
Q_{\mathrm{w}} & =f\left(T_{\mathrm{r}}, T_{\mathrm{v}}, T_{\mathrm{e}}\right) \\
Q_{\mathrm{ev}}=\dot{m}_{\mathrm{l}} h_{\mathrm{lv}} & =f\left(T_{\mathrm{r}}, T_{\mathrm{v}}, T_{\mathrm{we}}\right) \\
Q_{\mathrm{b}} & =f\left(T_{\mathrm{r}}, T_{\mathrm{e}}\right) \\
Q_{\mathrm{ext}, \mathrm{e}} & =f\left(T_{\mathrm{r}}, T_{\mathrm{e}}\right)
\end{aligned}
$$

$Q_{\text {ext,e }}$ is also a function of $T_{\text {ext }}$, which is a given data of our model. As a result, the heat load $Q_{\text {in }}$ can also be expressed as a function of these four temperatures:

$$
Q_{\text {in }}=f\left(T_{\mathrm{r}}, T_{\mathrm{v}}, T_{\mathrm{we}}, T_{\mathrm{e}}\right)
$$

An analytical expression of $Q_{\text {in }}$ will be derived in subsections 2.2 and 2.3. The part of $Q_{\mathrm{w}}$ that is not dissipated by evaporation is the transversal parasitic heat flux. Part of this flux is conducted through the wick and released to the

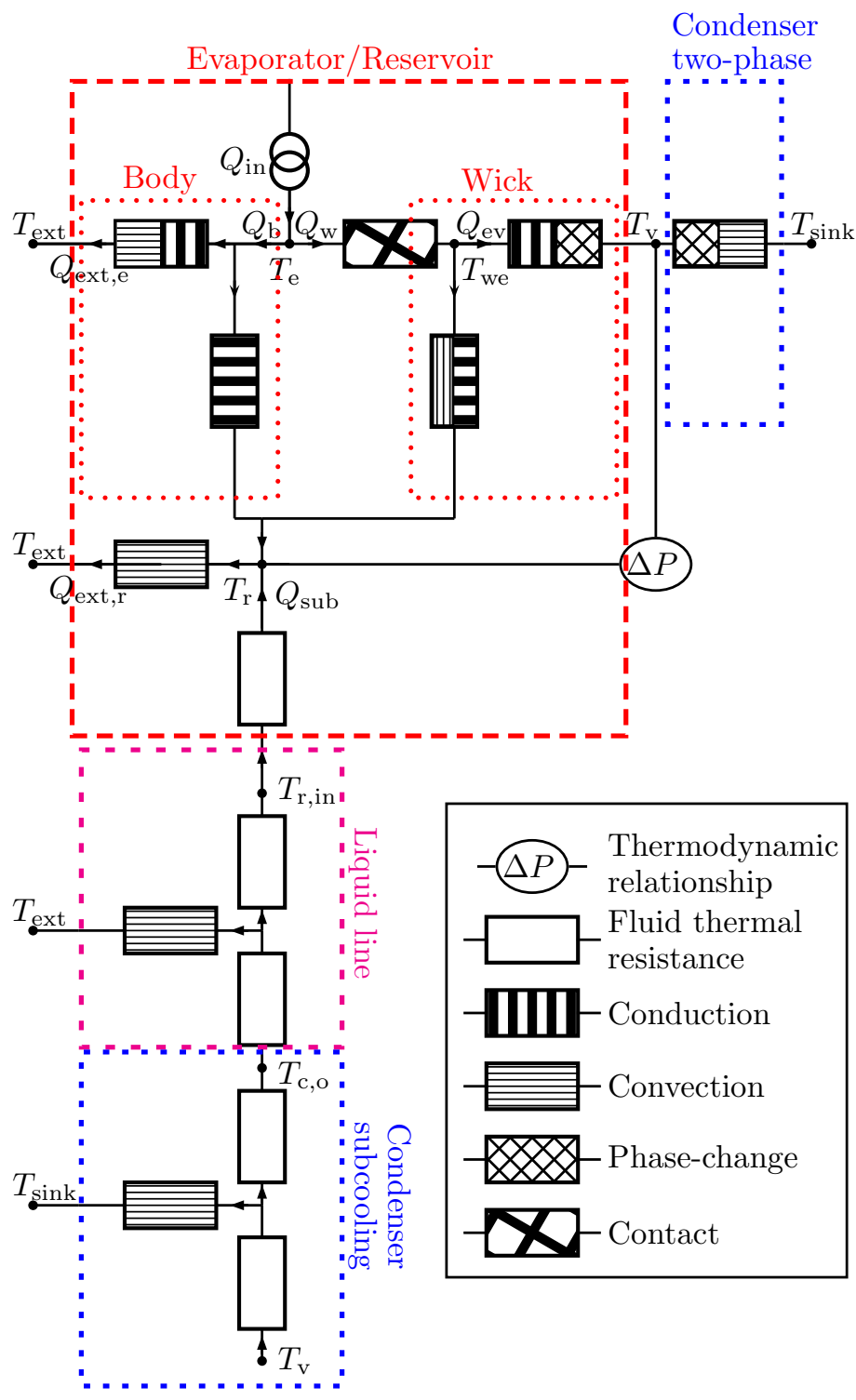

Figure 1: LHP schematic nodal network

reservoir whereas the rest is dissipated by convection due to the liquid flow inside the porous structure. At the interface between the wick and the evaporator envelope, there is a temperature gap $T_{\mathrm{e}}-T_{\mathrm{we}}$ due to a contact resistance $R_{\mathrm{c}}$ defined as:

$$
R_{\mathrm{c}}=S_{\mathrm{c}} \frac{T_{\mathrm{e}}-T_{\mathrm{we}}}{Q_{\mathrm{w}}}
$$

where $S_{\mathrm{c}}$ is the contact surface between the wick and the evaporator body and $T_{\mathrm{e}}$ and $T_{\mathrm{we}}$ are the temperatures on the envelope side and on the wick side, respectively.

A global heat balance on the evaporator/reservoir gives the following equation:

$$
Q_{\mathrm{in}}=Q_{\mathrm{ev}}+Q_{\mathrm{sen}}+Q_{\mathrm{sub}}+Q_{\mathrm{ext}, \mathrm{e}}+Q_{\mathrm{ext}, \mathrm{r}}
$$

where $Q_{\text {sen }}$ is the sensible heat given to the liquid, $Q_{\text {sub }}$ is the subcooling due to the liquid entering the reservoir 
and $Q_{\text {ext,r }}$ is the heat flux dissipated to the ambient by the reservoir. The determination of $Q_{\text {sen }}$ and $Q_{\text {sub leads to: }}$

$$
\begin{aligned}
& Q_{\text {sen }}=\dot{m}_{1} c_{\mathrm{p}, 1}\left(T_{\mathrm{v}}-T_{\mathrm{r}}\right) \\
& Q_{\mathrm{sub}}=\dot{m}_{1} c_{\mathrm{p}, \mathrm{l}}\left(T_{\mathrm{r}}-T_{\mathrm{r}, \text { in }}\right)
\end{aligned}
$$

where $T_{\mathrm{r}, \text { in }}$ is the temperature of the liquid coming from the condenser and flowing back to the reservoir.

To evaluate the heat transfer given by the reservoir to the ambient, it is assumed that its surface is at a uniform temperature equal to $T_{\mathrm{r}}$. Heat transfer with the ambient $Q_{\text {ext,r }}$ is then approximated by:

$$
Q_{\text {ext,r }}=h_{\text {ext }} S_{\mathrm{r}}\left(T_{\mathrm{r}}-T_{\text {ext }}\right)
$$

where $S_{\mathrm{r}}$ is the total external surface of the reservoir. A single expression of $Q_{\text {in }}$ can be derived by combining equations (3), (5) and (7) to (11):

$$
Q_{\text {in }}=f\left(T_{\mathrm{r}}, T_{\mathrm{v}}, T_{\mathrm{we}}, T_{\mathrm{e}}, \dot{m}_{\mathrm{l}}, T_{\mathrm{r}, \text { in }}\right)
$$

In some cases, the reservoir can be full of liquid. This phenomenon has been extensively studied by Adoni et al.[12]. In the present model, the existence of a two-phase equilibrium in the reservoir is assumed. As shown by Launay et al. [8], a thermodynamic relationship exists between the saturation temperature inside the grooves and the one at the liquid-vapour interface in the reservoir:

$$
\Delta T=T_{\mathrm{v}}-T_{\mathrm{r}}=\left(\frac{\partial T}{\partial P}\right)\left(\Delta P_{\mathrm{v}}+\Delta P_{1}-\rho_{\mathrm{l}} g \Delta H\right)
$$

where $\rho_{\mathrm{l}}$ is the liquid density and $\Delta H$ is the elevation of the condenser compared to the evaporator. The slope of the pressure-temperature saturation curve is given by the Clausius-Clapeyron equation:

$$
\frac{\partial T}{\partial P}=\frac{T\left(1 / \rho_{\mathrm{v}}-1 / \rho_{\mathrm{l}}\right)}{h_{\mathrm{lv}}}
$$

The model can also cope with non-condensable gases (NCG), which can be generated for various reasons in the LHP and accumulate in the reservoir, as explained by Singh et al. [13]. We assume that in operating conditions, these NCG are drained to the reservoir. In order to take into account the overpressure generated by the NCG $P_{\mathrm{NCG}}$, equation (13) is modified:

$$
\Delta T=T_{\mathrm{v}}-T_{\mathrm{r}}=\left(\frac{\partial T}{\partial P}\right)\left(\Delta P_{\mathrm{v}}+\Delta P_{1}-\rho_{\mathrm{l}} g \Delta H+P_{\mathrm{NCG}}\right)
$$

The vapour line is considered adiabatic so that the vapour enters the condenser with a temperature equal to $T_{\mathrm{v}}$. Furthermore, the condensation temperature $T_{\mathrm{c}}$ and the vapour temperature $T_{\mathrm{v}}$ are linked with the thermodynamic relationship (14). Since the pressure drops in the vapour line are low, it is assumed that condensation occurs at temperature $T_{\mathrm{v}}\left(T_{\mathrm{c}} \approx T_{\mathrm{v}}\right)$.

In the part of the condenser where liquid subcooling occurs, heat transfer with the heat sink and with the ambient are calculated considering a convective heat transfer $h_{\text {sink }}$ and $h_{\text {ext }}$, respectively:

$$
\begin{aligned}
T_{\mathrm{c}, \mathrm{o}}=T_{\text {sink }}+ & \left(T_{\mathrm{v}}-T_{\text {sink }}\right) \\
& \times \exp \left(\frac{-\pi D_{\mathrm{c}, \mathrm{i}}\left(L_{\mathrm{c}}-L_{2 \phi}\right)}{\dot{m}_{\mathrm{l}} c_{\mathrm{p}, \mathrm{l}}\left(1 / h_{\mathrm{l}}+D_{\mathrm{c}, \mathrm{i}} /\left(h_{\mathrm{sink}} D_{\mathrm{c}, \mathrm{o}}\right)\right)}\right)
\end{aligned}
$$

where $T_{\mathrm{c}, \mathrm{o}}$ is the temperature of the liquid at the condenser outlet, $L_{\mathrm{c}}$ and $L_{2 \phi}$ are the lengths of the condenser and of the two-phase region respectively. $D_{\mathrm{c}, \mathrm{i}}$ and $D_{\mathrm{c}, \mathrm{o}}$ are the inner and outer condenser diameters. In a similar way, the liquid line heat balance is:

$$
\begin{aligned}
T_{\mathrm{r}, \text { in }}=T_{\text {ext }}+ & \left(T_{\mathrm{c}, \mathrm{o}}-T_{\text {ext }}\right) \\
& \times \exp \left(\frac{-\pi D_{\mathrm{l}, \mathrm{i}} L_{\mathrm{l}}}{\dot{m}_{\mathrm{l}} c_{\mathrm{p}, \mathrm{l}}\left(1 / h_{\mathrm{l}}+D_{\mathrm{l}, \mathrm{i}} /\left(h_{\mathrm{ext}} D_{\mathrm{l}, \mathrm{o}}\right)\right)}\right)
\end{aligned}
$$

where $D_{1, \mathrm{i}}$ and $D_{1, \mathrm{o}}$ are the inner and outer diameters of the liquid line and $L_{l}$ its length. Additionally, in the condenser, the heat exchange with the heat sink in the twophase zone is equal to the latent heat of the condensing vapour:

$$
\dot{m}_{\mathrm{l}} h_{\mathrm{lv}}=\frac{1}{\frac{1}{h_{\mathrm{cond}} D_{\mathrm{c}, \mathrm{i}}}+\frac{1}{h_{\mathrm{sink}} D_{\mathrm{c}, \mathrm{o}}}} \pi L_{2 \phi}\left(T_{\mathrm{v}}-T_{\text {sink }}\right)
$$

Equations (3), (7), (8), (12), (15) to (17) and (18) form a set of 8 independent equations with 8 unknowns: $T_{\text {we }}$, $T_{\mathrm{e}}, T_{\mathrm{r}}, T_{\mathrm{r}, \mathrm{in}}, T_{\mathrm{c}, \mathrm{o}}, T_{\mathrm{v}}, \dot{m}_{\mathrm{l}}$ and $L_{2 \phi}$. Their solution leads to the determination of the complete thermal state of the LHP. The values of $Q_{\mathrm{b}}, Q_{\mathrm{w}}$ and $Q_{\mathrm{ev}}$ (equations 2-4) can be calculated using several methods. In the large majority of LHP models from the literature, heat transfer in the evaporator is simply described using equivalent thermal resistances based on the geometrical characteristics and the thermophysical properties of the evaporator. However, such a method does not take into account adequately the heat flux in the wick and the evaporator body since the determination of the thermal resistances requires a $2 \mathrm{D}$ or 3D approach. Thus, in the present study, an accurate thermal analysis of the evaporator has been conducted, based on an analytical approach.

\subsection{Analytical Thermal Model of the Wick}

The first part of the analytical model of the evaporator deals with heat and mass transfer inside the porous structure. As shown in Figure 2, a part of the porous wick is modelled, bordered on one side by the liquid bulk of the reservoir and by half of a fin and half of a groove on the other side.

The 2-D stationary heat equation in the wick is expressed as:

$$
\frac{\partial^{2} T_{\mathrm{w}}}{\partial x^{2}}+\frac{\partial^{2} T_{\mathrm{w}}}{\partial y^{2}}=0
$$

where $T_{\mathrm{w}}$ is the temperature of the porous structure and $x$ and $y$ are the axis coordinates (Fig. 3). A non-dimensional temperature is defined as:

$$
T_{\mathrm{w}}^{*}=\frac{\lambda_{\mathrm{eff}}\left(T_{\mathrm{w}}-T_{\mathrm{r}}\right)}{\phi_{0} b}
$$




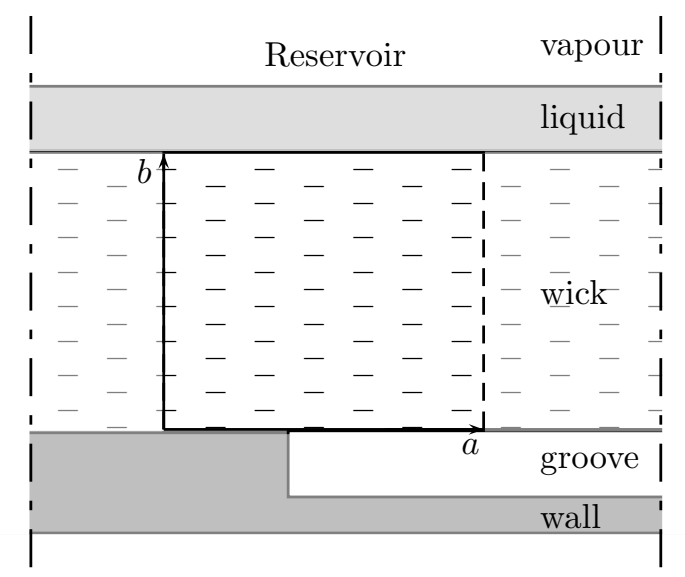

Figure 2: Evaporator cross-section

and leads to:

$$
\frac{\partial^{2} T_{\mathrm{w}}^{*}}{\partial X^{2}}+\frac{1}{B^{2}} \frac{\partial^{2} T_{\mathrm{w}}^{*}}{\partial Y^{2}}=0
$$

with

$$
X=\frac{x}{a}, \quad Y=\frac{y}{b} \quad \text { and } \quad B=\frac{b}{a}
$$

where $a$ and $b$ are the lengths of the modelled region in the $x$ and $y$ directions respectively, $\lambda_{\text {eff }}$ is the wick effective thermal conductivity and $\phi_{0}$ is an arbitrary heat flux.

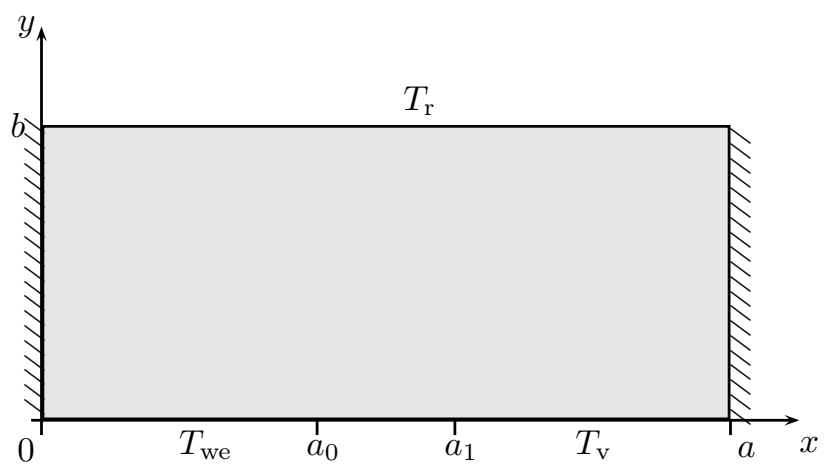

Figure 3: Schematic of the wick model

A general expression of the non-dimensional temperature field expanded in 2-D Fourier series is given by:

$$
T_{\mathrm{w}}^{*}(X, Y)=\sum_{m=0}^{\infty} A_{\mathrm{m}}(Y) \cos (m \pi X)+B_{\mathrm{m}}(Y) \sin (m \pi X)
$$

For $X=0$ and $X=1$, an adiabatic boundary condition is considered based on a symmetry hypothesis:

$$
\left.\frac{\partial T_{\mathrm{w}}^{*}}{\partial X}\right|_{X=0}=\left.\frac{\partial T_{\mathrm{w}}^{*}}{\partial X}\right|_{X=1}=0
$$

Thus equation (23) becomes:

$$
T_{\mathrm{w}}^{*}(X, Y)=\sum_{m=0}^{\infty} A_{\mathrm{m}}(Y) \cos (m \pi X)
$$

Combining equations (21) and (25) yields:

$$
-(m \pi B)^{2} A_{\mathrm{m}}(Y)+\frac{\partial^{2} A_{\mathrm{m}}(Y)}{\partial Y^{2}}=0
$$

Solving the previous differential equation leads to:

$$
\begin{aligned}
& A_{0}(Y)=A_{01} Y+A_{02} \quad \text { if } m=0 \\
& A_{\mathrm{m}}(Y)=A_{\mathrm{m} 1} e^{m \pi B Y}+A_{\mathrm{m} 2} e^{-m \pi B Y} \quad \text { otherwise }
\end{aligned}
$$

The boundary condition for $Y=0$ is a set temperature profile corresponding to the evaporator temperature $T_{\text {we }}$ for one side $\left(x \leqslant a_{0}\right)$ and to the groove temperature $T_{\mathrm{v}}$ for the other side $\left(x \geqslant a_{1}\right)$. At the junction between the wall and the groove, the temperature singularity is treated by considering a linear variation of the temperature between two fictive points $a_{0}$ and $a_{1}$. The slope of the temperature gradient and thus the position of these points depend on the maximum evaporation rate at the liquid-vapour interface that can be calculated using the kinetic gas theory, which gives a heat transfer coefficient $h_{\mathrm{ev}}[14]$ :

$$
h_{\mathrm{ev}}=\frac{2 a_{\mathrm{ev}}}{2-a_{\mathrm{ev}}} \frac{\rho_{\mathrm{v}} h_{\mathrm{lv}}^{2}}{T_{\mathrm{sat}}}\left(\frac{2 \pi \bar{R} T_{\mathrm{sat}}}{\bar{M}}\right)^{-0.5}\left(1-\frac{P_{\mathrm{sat}}}{2 \rho_{\mathrm{v}} h_{\mathrm{lv}}}\right)
$$

where $a_{\mathrm{ev}}$ is the accommodation coefficient. Such an approach was already used in [15] to cope numerically with the temperature singularity at the triple line. In the case of the evaporation of a thin liquid film, the accommodation coefficient is defined as the ratio of the actual evaporation rate to a theoretical maximal phase change rate. A coefficient equal to unity describes perfect evaporation while a lower value represents incomplete evaporation. In the case of water, values varying from 0.01 to 1 are suggested in the literature [16]. We assume the following relationship between $h_{\mathrm{ev}}$ and the position of $a_{0}$ and $a_{1}$ :

$$
h_{\mathrm{ev}}=\frac{\lambda_{\mathrm{eff}}}{a_{1}-a_{0}}
$$

The boundary condition for $Y=0$ is then defined as:

$$
T_{\mathrm{w}}^{*}(X, 0)=\left\{\begin{array}{lc}
\frac{\lambda_{\text {eff }}\left(T_{\mathrm{we}}-T_{\mathrm{r}}\right)}{\phi_{0} b} & \text { if } 0<X \leqslant \frac{a_{0}}{a} \\
\left.\frac{\lambda_{\text {eff }}\left(\left(T_{\mathrm{v}}-T_{\mathrm{r}}\right)+\left(T_{\mathrm{we}}-T_{\mathrm{v}}\right) \frac{a_{1}-a X}{\phi_{0} b}\right)}{a_{1}-a_{0}}\right) & \text { if } \frac{a_{0}}{a}<X<\frac{a_{1}}{a} \\
\frac{\lambda_{\text {eff }}\left(T_{\mathrm{v}}-T_{\mathrm{r}}\right)}{\phi_{0} b} & \text { if } \frac{a_{1}}{a} \leqslant X<1
\end{array}\right.
$$

For $Y=1$, the reservoir temperature is set:

$$
T_{\mathrm{w}}^{*}(X, 1)=0
$$


The non-dimensional temperature field is then:

$$
\begin{aligned}
T_{\mathrm{w}}^{*}(X, Y) & =A_{01} Y+A_{02} \\
& +\sum_{m=1}^{\infty}\left(A_{\mathrm{m} 1} e^{m \pi B Y}+A_{\mathrm{m} 2} e^{-m \pi B Y}\right) \cos (m \pi X)
\end{aligned}
$$

with

$$
\begin{aligned}
& A_{01}=-\frac{\lambda_{\text {eff }}}{\phi_{0} b}\left(T_{\mathrm{v}}-T_{\mathrm{r}}+\left(T_{\mathrm{we}}-T_{\mathrm{v}}\right) \frac{a_{0}+a_{1}}{2 a}\right) \\
& A_{02}=\frac{\lambda_{\text {eff }}}{\phi_{0} b}\left(T_{\mathrm{v}}-T_{\mathrm{r}}+\left(T_{\mathrm{we}}-T_{\mathrm{v}}\right) \frac{a_{0}+a_{1}}{2 a}\right) \\
& A_{\mathrm{m} 1}=2 \frac{\lambda_{\mathrm{eff}}}{\phi_{0} b} \frac{T_{\mathrm{we}}-T_{\mathrm{v}}}{m^{2} \pi^{2}} \frac{a}{a_{1}-a_{0}} \frac{\cos \left(m \pi \frac{a_{0}}{a}\right)-\cos \left(m \pi \frac{a_{1}}{a}\right)}{1-e^{2 m \pi B}} \\
& A_{\mathrm{m} 2}=2 \frac{\lambda_{\mathrm{eff}}}{\phi_{0} b} \frac{T_{\mathrm{we}}-T_{\mathrm{v}}}{m^{2} \pi^{2}} \frac{a}{a_{1}-a_{0}} \frac{\cos \left(m \pi \frac{a_{0}}{a}\right)-\cos \left(m \pi \frac{a_{1}}{a}\right)}{1-e^{-2 m \pi B}}
\end{aligned}
$$

In equation (33), the liquid flow inside the porous structure is not taken into account. This flow is twodimensional. However, in the present study, we assume a $1 \mathrm{D}$ flow inside the wick, considering a homogeneous volumetric source inside the wick $q$ defined as:

$$
q=-\frac{4 \dot{m}_{1} c_{\mathrm{p}, 1}\left(T_{\mathrm{v}}-T_{\mathrm{r}}\right)}{\pi D_{\mathrm{w}}^{2} b}
$$

where $\dot{m}_{1}$ is the total liquid mass flow rate in the wick and $c_{\mathrm{p}, \mathrm{l}}$ is the specific heat of the liquid. This assumption respects the energy balance and enables to derive an analytical expression for the influence of the liquid flow inside the wick. The superposition principle enables to add a simple model of heat transfer in the wick with a homogeneous source to the previous developed analysis. It has to be noted that a $2 \mathrm{D}$ approach of heat and mass transfer in a porous wick was presented by Cao and Faghri [17], but the model is not entirely analytical. The heat equation in the wick is thus:

$$
\frac{\partial^{2} T_{\mathrm{c}}}{\partial y^{2}}=\frac{q}{\lambda_{\mathrm{eff}}}
$$

and the boundary conditions are:

$$
\begin{aligned}
T_{\mathrm{c}}(y=0)-T_{\mathrm{c}}(y=b) & =b^{2} \frac{q}{\lambda_{\mathrm{eff}}} \\
T_{\mathrm{c}}(y=b) & =T_{\mathrm{r}}
\end{aligned}
$$

This leads to the non-dimensional temperature field implied by the liquid flow inside the wick:

$$
T_{\mathrm{c}}^{*}=\frac{q b}{2 \phi_{0}}\left(Y^{2}-3 Y+2\right)
$$

This solution is added to the previous one to give a general expression of the non-dimensional temperature field in the wick, with consideration of $1-\mathrm{D}$ convection:

$$
T_{\mathrm{t}}^{*}=T_{\mathrm{w}}^{*}+T_{\mathrm{c}}^{*}
$$

The previously described model enables to calculate the heat flux through the wick $Q_{\mathrm{w}}$ and the heat dissipated by evaporation $Q_{\mathrm{ev}}$ :

$$
\begin{aligned}
Q_{\mathrm{w}}= & \frac{S_{\mathrm{w}}}{a} \int_{0}^{\frac{a_{0}+a_{1}}{2}}-\left.\lambda_{\mathrm{eff}} \frac{\partial T_{\mathrm{t}}}{\partial y}\right|_{y=0} d x \\
= & -S_{\mathrm{w}} \phi_{0}\left[\frac{a_{0}+a_{1}}{2 a}\left(A_{01}-\frac{3 q b}{2 \phi_{0}}\right)\right. \\
& \left.\quad+\sum_{m=1}^{\infty} B\left(A_{\mathrm{m} 1}-A_{\mathrm{m} 2}\right) \sin \left(m \pi \frac{a_{0}+a_{1}}{2 a}\right)\right] \\
Q_{\mathrm{ev}}= & \left.\frac{S_{\mathrm{w}}}{a} \int_{\frac{a_{0}+a_{1}}{2}}^{a} \lambda_{\mathrm{eff}} \frac{\partial T_{\mathrm{t}}}{\partial y}\right|_{y=0} d x \\
= & S_{\mathrm{w}} \phi_{0}\left[\left(1-\frac{a_{0}+a_{1}}{2 a}\right)\left(A_{01}-\frac{3 q b}{2 \phi_{0}}\right)\right. \\
& \left.\quad-\sum_{m=1}^{\infty} B\left(A_{\mathrm{m} 1}-A_{\mathrm{m} 2}\right) \sin \left(m \pi \frac{a_{0}+a_{1}}{2 a}\right)\right]
\end{aligned}
$$

\subsection{Analytical Thermal Model of the Evaporator Body}

The model of the wick is sufficient if the heat losses through the evaporator body are negligible. Nevertheless, the body is usually made of a high conductive material. Therefore, it is generally necessary to estimate the heat transferred by conduction from the evaporator to the reservoir and to the ambient. A second analytical model is developed to describe the evaporator casing. As shown in Figure 4, the evaporator wall is "unwrapped" and modelled as a rectangular domain. At $x=0$ and $x=c$, an adiabatic condition is assumed due to the symmetry. At $y=0$, a convective heat transfer with the ambient is taken into account on the whole external surface, including the heating section $\left(0 \leqslant x \leqslant c_{0}\right)$, where a heat flux $\phi_{\text {in }}$ is also applied. The inner part of the body is highly influenced by the reservoir temperature. The rectangular shape chosen to represents the evaporator body does not consider the effect of the grooves on the distortion of the temperature field between the base plate and the wick. We assume, therefore, a set temperature profile, with the evaporator temperature $T_{\mathrm{e}}$ on one side $\left(0 \leqslant x \leqslant c_{0}\right)$ and the reservoir temperature $T_{\mathrm{r}}$ on the other side $\left(c_{1} \leqslant x \leqslant c\right)$ with a linear profile in-between.

The sum of two solutions is necessary to take into account the complete set of boundary conditions. The first one corresponds to a set temperature profile in the inner part of the wall, in contact with the wick and the liquidvapour bulk in the reservoir. Convective heat losses to the ambient are assumed for the whole external surface of the evaporator/reservoir. This hypothesis considers that the electronic component to cool down dissipates heat with the LHP on one side and with the ambient on the other. The second solution adds the heat input to the evaporator. 

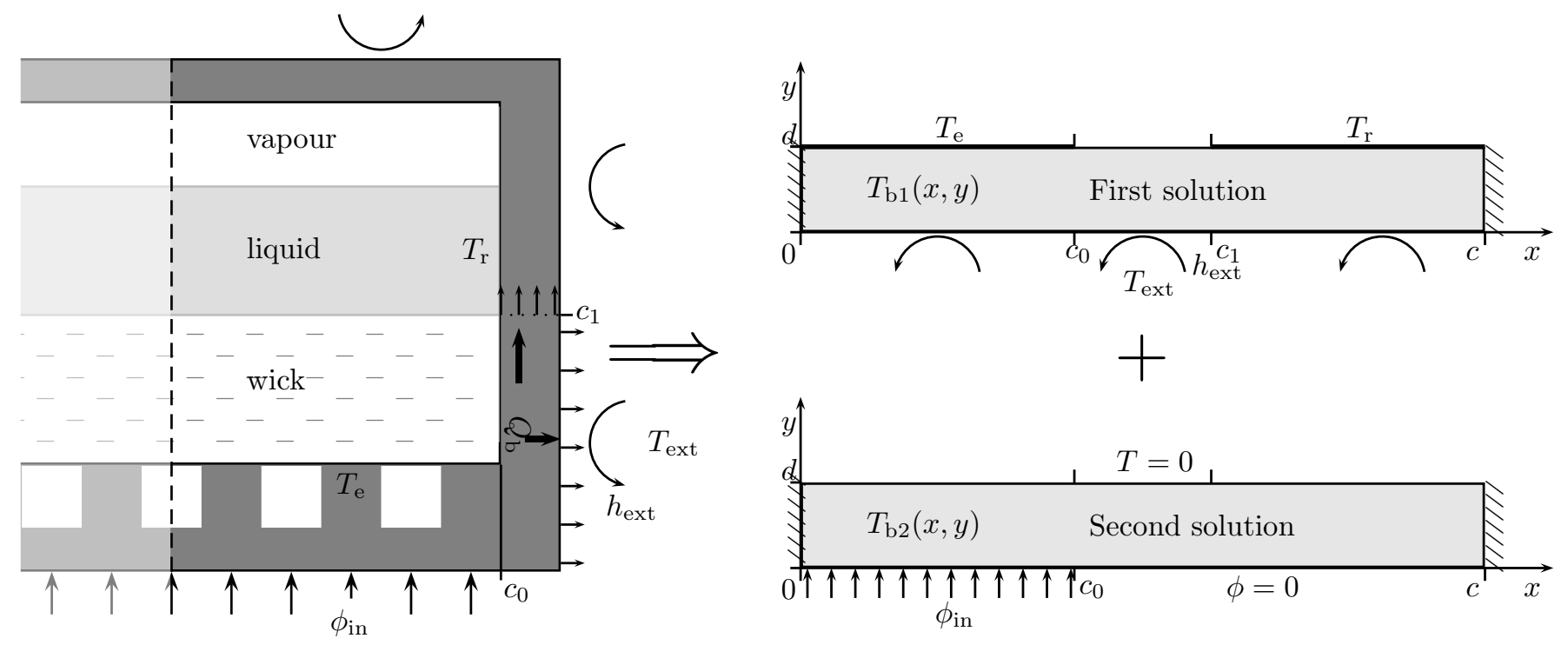

Figure 4: Evaporator casing modelling

Using the same mathematical procedure as previously, the heat equation becomes:

$$
\frac{\partial^{2} T_{\mathrm{b}}^{*}}{\partial X^{2}}+\frac{1}{D^{2}} \frac{\partial^{2} T_{\mathrm{b}}^{*}}{\partial Y^{2}}=0
$$

where:

$$
X=\frac{x}{c} ; \quad Y=\frac{y}{d} ; \quad D=\frac{d}{c} ; \quad T_{\mathrm{b}}^{*}=\frac{\lambda_{\mathrm{b}}\left(T_{\mathrm{b}}-T_{\mathrm{r}}\right)}{\phi_{0} d}
$$

The boundary conditions for the first solution $T_{\mathrm{b} 1}^{*}$ are:

$$
\begin{aligned}
& \left.\frac{\left.\partial T_{\mathrm{b} 1}^{*}\right|_{X=0}=}{\partial X}\right|_{X=1}=0 \quad \text { (symmetry) } \\
& \frac{\left.\partial T_{\mathrm{b} 1}^{*}\right|_{Y=0} ^{*}=}{\text { with } \quad B i_{\mathrm{b}}=\frac{d h_{\mathrm{ext}}}{\lambda_{\mathrm{b}}}} \\
& T_{\mathrm{b} 1}^{*}(X, 1)= \begin{cases}\frac{\lambda_{\mathrm{b}}\left(T_{\mathrm{e}}-T_{\mathrm{r}}\right)}{\phi_{0} d} & \text { if } 0<X \leqslant \frac{c_{0}}{c} \\
\frac{\lambda_{\mathrm{b}}}{\phi_{0} d}\left(T_{\mathrm{e}}-T_{\mathrm{r}}\right) \frac{c_{1}-c X}{c_{1}-c_{0}} & \text { if } \frac{c_{0}}{c} \leqslant X<\frac{c_{1}}{c} \\
0 & \text { if } \frac{c_{1}}{c}<X<1\end{cases}
\end{aligned}
$$

whereas for the second solution $T_{\mathrm{b} 2}^{*}$ :

$$
\begin{aligned}
& \left.\left.\frac{\left.\partial T_{\mathrm{b} 2}^{*}\right|_{X=0}}{\partial X}\right|_{X=} \frac{\partial T_{\mathrm{b} 2}^{*}}{\partial X}\right|_{X=1}=0 \\
& \frac{\left.\partial T_{\mathrm{b} 2}^{*}\right|_{Y=0}}{\partial Y} \begin{cases}-\frac{\phi_{\mathrm{in}}}{\phi_{0}} & \text { if } 0<X \leqslant \frac{c_{0}}{c} \\
0 & \text { if } X>\frac{c_{0}}{c}\end{cases} \\
& T_{\mathrm{b} 2}^{*}(X, 1)=0
\end{aligned}
$$

The combination of equations (46) to (53) and the addition of both solutions lead to the non-dimensional temperature field in the evaporator body:

$$
\begin{aligned}
T_{\mathrm{b}}^{*}(X, Y) & =C_{01} Y+C_{02} \\
& +\sum_{m=1}^{\infty}\left(C_{\mathrm{m} 1} e^{m \pi D Y}+C_{\mathrm{m} 2} e^{-m \pi D Y}\right) \cos (m \pi X)
\end{aligned}
$$

with

$$
\begin{aligned}
& C_{01}=\frac{B i_{\mathrm{b}}}{B i_{\mathrm{b}}+1} \frac{\lambda_{\mathrm{b}}}{\phi_{0} d}\left(\left(T_{\mathrm{e}}-T_{\mathrm{r}}\right) \frac{c_{0}+c_{1}}{2 c}+\left(T_{\mathrm{r}}-T_{\mathrm{ext}}\right)\right) \\
& -\frac{c_{0}}{c} \frac{\phi_{\text {in }}}{\phi_{0}} \\
& C_{02}=\frac{1}{B i_{\mathrm{b}}+1} \frac{\lambda_{\mathrm{b}}}{\phi_{0} d}\left(\left(T_{\mathrm{e}}-T_{\mathrm{r}}\right) \frac{c_{0}+c_{1}}{2 c}-B i_{\mathrm{b}}\left(T_{\mathrm{r}}-T_{\mathrm{ext}}\right)\right) \\
& +\frac{c_{0}}{c} \frac{\phi_{\text {in }}}{\phi_{0}} \\
& C_{\mathrm{m} 1}=2 \frac{\lambda_{\mathrm{b}}}{\phi_{0} d} \frac{T_{\mathrm{e}}-T_{\mathrm{r}}}{m^{2} \pi^{2}} \frac{c}{c_{1}-c_{0}} \frac{\cos \left(m \pi \frac{c_{0}}{c}\right)-\cos \left(m \pi \frac{c_{1}}{c}\right)}{e^{m \pi D}+\frac{m \pi D+B i_{\mathrm{b}}}{m \pi D-B i_{\mathrm{b}}} e^{-m \pi D}} \\
& -2 \frac{\phi_{\text {in }}}{\phi_{0}} \frac{1}{m^{2} \pi^{2} D} \sin \left(m \pi \frac{c_{0}}{c}\right) \frac{1}{1+e^{2 m \pi D}} \\
& C_{\mathrm{m} 2}=2 \frac{\lambda_{\mathrm{b}}}{\phi_{0} d} \frac{T_{\mathrm{e}}-T_{\mathrm{r}}}{m^{2} \pi^{2}} \frac{c}{c_{1}-c_{0}} \frac{\cos \left(m \pi \frac{c_{0}}{c}\right)-\cos \left(m \pi \frac{c_{1}}{c}\right)}{e^{-m \pi D}+\frac{m \pi D-B i_{\mathrm{b}}}{m \pi D+B i_{\mathrm{b}}} e^{m \pi D}} \\
& +2 \frac{\phi_{\mathrm{in}}}{\phi_{0}} \frac{1}{m^{2} \pi^{2} D} \sin \left(m \pi \frac{c_{0}}{c}\right) \frac{1}{1+e^{-2 m \pi D}}
\end{aligned}
$$

The heat dissipated to the ambient in the evaporator section of the body is:

$$
\begin{aligned}
Q_{\text {ext }, \mathrm{e}} & =\int_{0}^{c_{0}} h_{\mathrm{ext}} \pi x\left(T_{\mathrm{b}}(x, 0)-T_{\mathrm{ext}}\right) d x \\
& +\int_{c_{0}}^{c_{1}} h_{\mathrm{ext}} \pi c_{0}\left(T_{\mathrm{b}}(x, 0)-T_{\mathrm{ext}}\right) d x \\
& =h_{\mathrm{ext}} \pi c_{0}\left(c_{1}-\frac{c_{0}}{2}\right)\left(T_{\mathrm{r}}-T_{\mathrm{ext}}+\frac{\phi_{0} d}{\lambda_{\mathrm{b}}} C_{02}\right)
\end{aligned}
$$




$$
\begin{aligned}
+ & h_{\mathrm{ext}} \pi \frac{\phi_{0} d}{\lambda_{\mathrm{b}}} \sum_{m=1}^{\infty}\left(C_{\mathrm{m} 1}+C_{\mathrm{m} 2}\right) \frac{c}{m \pi} \\
& \times\left(\frac{c}{m \pi}\left(-1+\cos \left(\frac{m \pi c_{0}}{2}\right)\right)+\frac{c_{0}}{m \pi} \sin \left(m \pi \frac{c_{1}}{c}\right)\right)
\end{aligned}
$$

The heat transferred by thermal conduction through the evaporator body to the reservoir section is calculated by integrating the Fourier's law at $y=c_{1}$ (Fig. 4). Thus, the total heat losses through the body is:

$$
\begin{aligned}
Q_{\mathrm{b}}= & Q_{\mathrm{ext}, \mathrm{e}}+\int_{0}^{d}-\left.\pi c_{0} \lambda_{\mathrm{b}} \frac{\partial T_{\mathrm{b}}}{\partial x}\right|_{x=c_{1}} d y \\
= & Q_{\mathrm{ext}, \mathrm{e}}+d c_{0} \phi_{0} \sum_{m=1}^{\infty} \pi \sin \left(m \pi \frac{c_{1}}{c}\right) \\
& \quad \times\left(C_{\mathrm{m} 1}\left(e^{m \pi D}-1\right)-C_{\mathrm{m} 2}\left(e^{-m \pi D}-1\right)\right)
\end{aligned}
$$

\subsection{Solving procedure}

The solving procedure is presented in Figure 5. The set of equations is not linear. Thus an iterative procedure is used to solve it. After initialisation of the parameters of the model, the two-phase length in the condenser $L_{2 \phi}$ is set, according to the energy balance for a given heat input $Q_{\text {in }}(18) . L_{2 \phi}$ has a major influence on the determination of the temperature of the liquid entering in the reservoir $T_{\mathrm{r}, \text { in }}$ (equations 16-17). Then, the thermophysical properties are calculated, as well as the pressure drops in the transport lines.

K-coefficients can be defined to reformat the expression of $Q_{\mathrm{w}}, Q_{\mathrm{ev}}, Q_{\mathrm{b}}$ and $T_{\mathrm{r}, \text { in }}$ as functions of $T_{\mathrm{r}}, T_{\mathrm{v}}, T_{\mathrm{e}}$ and $T_{\text {we }}$ :

$$
\begin{array}{rlr}
Q_{\mathrm{w}} & =K_{1} T_{\mathrm{r}}+K_{2} T_{\mathrm{v}}+K_{3} T_{\mathrm{we}} & \text { using }(34,36,37,44) \\
Q_{\mathrm{ev}} & =K_{4} T_{\mathrm{r}}+K_{5} T_{\mathrm{v}}+K_{6} T_{\mathrm{we}} & \text { using }(34,36,37,45) \\
Q_{\mathrm{ext}, \mathrm{e}} & =K_{10} T_{\mathrm{r}}+K_{11} T_{\mathrm{e}}+K_{12} & \text { using }(56,57,58,59) \\
Q_{\mathrm{b}} & =K_{7} T_{\mathrm{r}}+K_{8} T_{\mathrm{e}}+K_{9} & \\
T_{\mathrm{r}, \text { in }} & =K_{13} T_{\mathrm{v}}+K_{14} & \text { using }(57,58,60,63)
\end{array}
$$

The detailed expression of these coefficients is presented in Appendix A. Equations (1,7-11, 15-17,61-65) are solved and give a second-order expression which enables to calculate the vapour temperature $T_{\mathrm{v}}$ (see Appendix B).

This procedure is iterated until the energy balance is satisfied in the condenser (equation 18). The same method is computed for each heat input $Q_{\text {in }}(i)$. Since the heat transfer coefficient with the heat sink is generally much lower than the condensation heat transfer coefficient, the condensation thermal resistance is neglected to simplify equation (18).

Equation (15) is a function of the pressure drops $\Delta P_{\mathrm{v}}$ and $\Delta P_{1}$. These parameters, due to the friction forces in

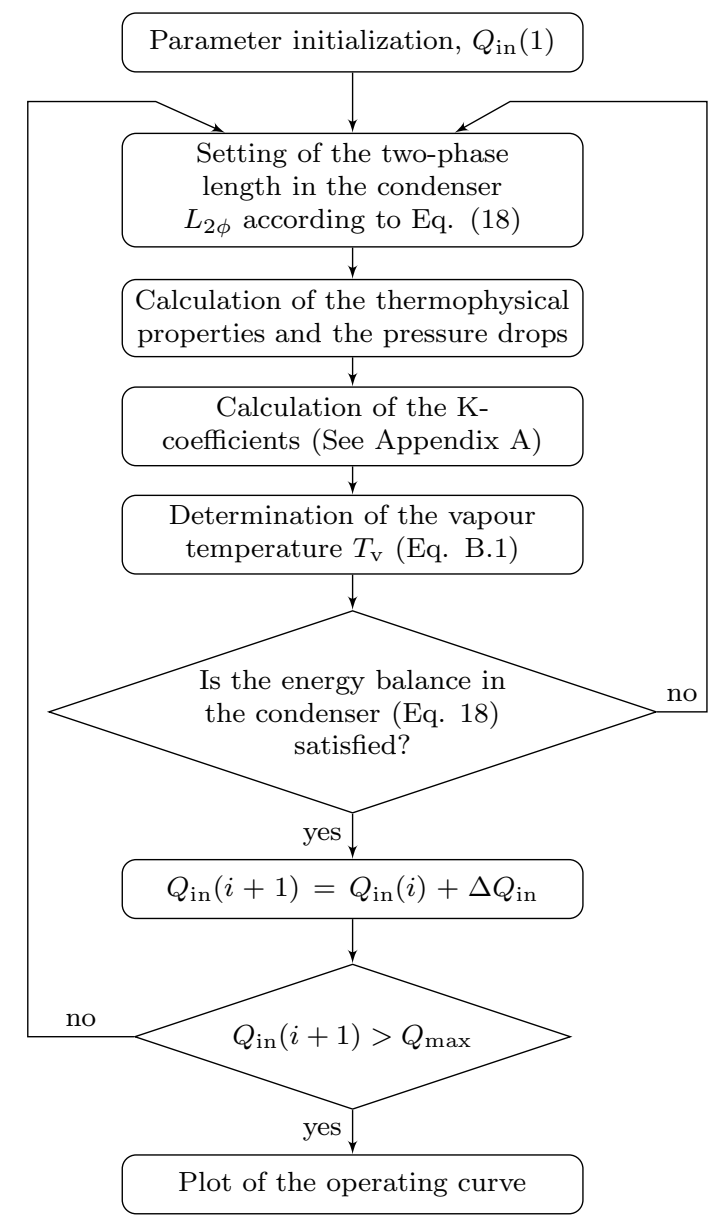

Figure 5: Solving algorithm flowchart

the vapour and the liquid lines, depend on the fluid flow regime. They are calculated as follows:

$$
\Delta P=\frac{f}{2 \rho D}\left(\frac{\dot{m}}{A}\right)^{2} L
$$

where $A$ is the cross-section area of the tube. For a smooth tube wall of diameter $D$ and length $L$, the friction factor $f$ is expressed by:

$$
f= \begin{cases}64 / R e & \text { if } \quad R e \leq 2000 \\ 0.032 & \text { if } \quad 2000<R e<9150 \\ 0.316 R e^{-0.25} & \text { if } \quad R e \geq 9150\end{cases}
$$

Equation (15) also includes the pressure of noncondensable gases $P_{\mathrm{NCG}}$. In order to take into account the NCG, it is necessary to calculate the liquid level in the reservoir that depends on the heat load. We assume that the void fraction of the two-phase flow in the condenser is 0.5 and that the vapour density is negligible compared to the liquid density. The liquid level $e_{1}$ in the reservoir is 
therefore expressed as:

$$
e_{\mathrm{l}}=\frac{1}{S_{\mathrm{w}}}\left(\frac{m_{\mathrm{f}}}{\rho_{\mathrm{l}}}-\varepsilon S_{\mathrm{w}} e_{\mathrm{w}}-\frac{L_{\mathrm{l}} \pi D_{1, \mathrm{i}}^{2}}{4}-\frac{\left(L_{\mathrm{c}}-\frac{1}{2} L_{2 \phi}\right) \pi D_{\mathrm{c}, \mathrm{i}}^{2}}{4}\right)
$$

where $m_{\mathrm{f}}$ is the total fluid charge in the system and $e_{\mathrm{w}}$ is the wick thickness. The total volume of NCG and vapour in the reservoir $V_{\mathrm{v}}$ is equal to:

$$
V_{\mathrm{v}}=S_{\mathrm{w}}\left(e_{\mathrm{r}}-e_{\mathrm{l}}\right)
$$

with $e_{\mathrm{r}}$ the thickness of the reservoir. Considering the noncondensable gases as ideal gases, their partial pressure is calculated by:

$$
P_{\mathrm{NCG}}=\frac{m_{\mathrm{NCG}} R T_{\mathrm{r}}}{M_{\mathrm{NCG}} V_{\mathrm{v}}}
$$

where $R$ is the ideal gas constant and $m_{\mathrm{NCG}}$ and $M_{\mathrm{NCG}}$ are the NCG total mass and the molar mass, respectively.

To solve equations (16-18), the heat sink heat transfer coefficient $h_{\text {sink }}$ is determined in accordance with the condenser design, whereas the heat transfer coefficient of the liquid $h_{1}$ is calculated assuming a laminar fully-developed flow and a constant Nusselt number $N u_{\mathrm{D}}=4.36$ [18].

Equations (11) and (17) depend on the heat transfer coefficient with the ambient $h_{\text {ext }}$. It is given by the correlation of Churchill and Chu [18] for free convection on the surface of an isothermal cylinder:

$$
h_{\mathrm{ext}}=\frac{\lambda_{\mathrm{air}}}{D}\left[0.60+\frac{0.387 R a_{\mathrm{D}}^{\frac{1}{6}}}{\left(1+(0.559 / P r)^{\frac{9}{16}}\right)^{\frac{8}{27}}}\right]^{2}
$$

This correlation is valid for Rayleigh numbers $R a_{\mathrm{D}}$ lower than $10^{12}$. The determination of the effective thermal conductivity of the porous structure will be discussed in the next section.

\section{Results and discussion}

This section presents a sensitivity analysis to show the influence of different parameters on the LHP performance. The LHP geometry considered for this analysis is similar to standard systems used for electronic cooling applications. Its geometrical characteristics are based on the experiments of Singh et al.[19] and Choi et al.[20]. A validation of the model is presented in the last paragraph.

\subsection{Standard case}

The properties of this "standard" LHP, having a flat disk-shaped evaporator, is defined in Table 1. The system is supposed to be in horizontal orientation. The wick is made of nickel and the working fluid is water. The main parameters for the wick are the effective thermal conductivity, the accommodation and the contact thermal resistance between the wick and the casing.
Extensive studies have been undertaken to develop models able to predict accurately the effective thermal conductivity of a porous structure. Thus, many different correlations can be found in the literature to determine the effective thermal conductivity of a porous material [21-24] Table 2 presents the results obtained for a nickel wick of $75 \%$ porosity saturated with water, using various correlations. This thermophysical property depends not only on the conductivity of the materials constituting the wick but also on geometrical parameters such as the porosity, the mean pore diameter and the pore size distribution. The results are very different according to the chosen correlation. This shows that this parameter is difficult to evaluate accurately. For the standard case, an effective thermal conductivity equal to $5 \mathrm{~W} \cdot \mathrm{m}^{-1} \cdot \mathrm{K}^{-1}$ is chosen, which corresponds to the wick properties of Singh et al.[19].

\begin{tabular}{|l|c|}
\hline Correlation & $\lambda_{\mathbf{e f f}}\left(\mathbf{W} \cdot \mathbf{m}^{-\mathbf{1}} \cdot \mathbf{K}^{-\mathbf{1}}\right)$ \\
\hline Alexander & 5.82 \\
\hline Chaudhary-Bandhari & 4.06 \\
\hline Maxwell & 16.96 \\
\hline Parallel scheme & 23 \\
\hline Zehner-Schlunder & 1.75 \\
\hline
\end{tabular}

Table 2: Effective thermal conductivity calculation with a watersaturated nickel wick, $75 \%$ porosity

Information from the literature concerning the thermal contact between a porous structure and a solid base plate is very scarce. This parameter depends on many geometrical and manufacturing characteristics. Choi et al. [20] investigated new techniques to enhance the thermal contact conductance of evaporators in LHPs. Several channel designs have been tested and compared. An estimation of the contact thermal resistance (including in practice thermal conduction in the base plate, in the wick and an evaporation resistance) is given and values ranging from $7 \cdot 10^{-5}$ to $3 \cdot 10^{-4} \mathrm{~m}^{2} \cdot \mathrm{K} \cdot \mathrm{W}^{-1}$ have been obtained. Based on this work, a constant contact resistance of $10^{-4} \mathrm{~m}^{2} \cdot \mathrm{K} \cdot \mathrm{W}^{-1}$ is chosen for the standard case.

Although the accommodation coefficient is a key parameter in the determination of the LHP temperature, its value is very difficult to predict. In the literature, several studies are dedicated to the determination of this parameter for various fluids[16]. However, the scattering of the results confirms the difficulty of describing the evaporation accurately. For water, values ranging from 0.01 to 1 have been found. Therefore, an accommodation coefficient equal to 0.1 is chosen for the standard case.

The temperatures at different locations in the LHP are plotted in Figure 6 for heat inputs ranging between $10 \mathrm{~W}$ and $110 \mathrm{~W}$. A temperature difference of several degrees between $T_{\mathrm{e}}$ and $T_{\mathrm{we}}$ shows the impact of the thermal contact resistance between the wick and the casing, particularly at high heat inputs. Since the mass flow rates in the transport lines and the condenser are moderate due to the high 


\begin{tabular}{|c|c|}
\hline Evaporator design & Flat disk-shaped \\
\hline Wick diameter & $40 \mathrm{~mm}$ \\
\hline Wick thickness & $3 \mathrm{~mm}$ \\
\hline Wick effective thermal conductivity & $5 \mathrm{~W} \cdot \mathrm{m}^{-1} \cdot \mathrm{K}^{-1}$ \\
\hline Vapour groove width & $1 \mathrm{~mm}$ \\
\hline Wick-wall contact resistance & $10^{-4} \mathbf{K} \cdot \mathbf{m}^{2} \cdot \mathbf{W}^{-1}$ \\
\hline Accommodation coefficient & 0.1 \\
\hline Reservoir depth & $10 \mathrm{~mm}$ \\
\hline Evaporator diameter & $41 \mathrm{~mm}$ \\
\hline Evaporator wall material & Stainless steel \\
\hline Working fluid & Water \\
\hline Fluid charge & $7 \mathrm{~g}$ \\
\hline Condenser and transport lines i/o diameters & $2 / 2.4 \mathrm{~mm}$ \\
\hline Transport lines length & $200 \mathrm{~mm}$ \\
\hline Condenser length & $100 \mathrm{~mm}$ \\
\hline Heat sink temperature & $22^{\circ} \mathrm{C}$ \\
\hline Heat transfer coefficient with the heat sink & $2000 \mathrm{~W} \cdot \mathrm{m}^{-2} \cdot \mathrm{K}^{-1}$ \\
\hline Ambient temperature & $22^{\circ} \mathrm{C}$ \\
\hline Heat transfer coefficient with the ambient & $5 \mathrm{~W} \cdot \mathrm{m}^{-2} \cdot \mathrm{K}^{-1}$ \\
\hline
\end{tabular}

Table 1: Definition of the standard LHP for the sensitivity analysis

latent heat of vaporization of water, pressure drops in the loop are not significant. Therefore, the saturation temperatures in the reservoir and in the grooves, $T_{\mathrm{r}}$ and $T_{\mathrm{v}}$, are almost equal. The values of $T_{\mathrm{c}, \mathrm{o}}$ and $T_{\mathrm{r}, \mathrm{in}}$ are also very similar because the heat transfer between the liquid line and the ambient is limited.

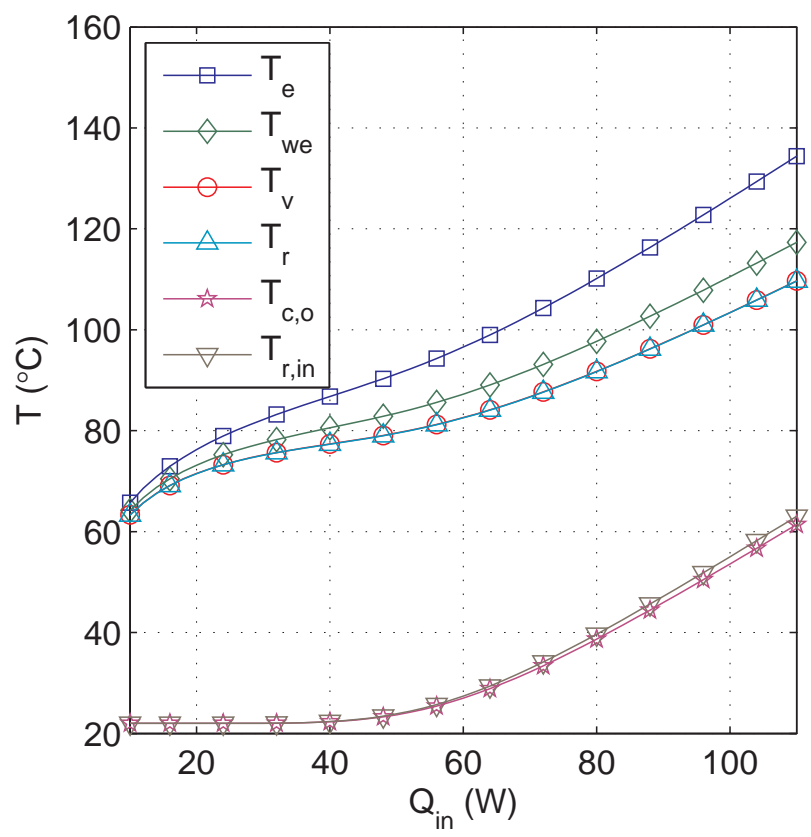

Figure 6: Temperature of the LHP in the standard case

A clear transition between the variable conductance mode and the fixed conductance mode is observed around $60 \mathrm{~W}$. For lower heat inputs, the temperature of the liquid exiting the condenser is constant and equal to the heat sink temperature. Above this point, $T_{\mathrm{c}, \mathrm{o}}$ starts to increase and the shape of all the temperature curves in the LHP is quasi-linear.

Figure 7 shows the temperature in the porous structure in the standard case, for a total heat load $Q_{\text {in }}$ of $50 \mathrm{~W}$. For $y=0 \mathrm{~mm}$, the temperature profile shows a sharp discontinuity at the transition between the groove and the fin. The intense evaporation occurring at $x=0.5 \mathrm{~mm}$ causes the convergence of the heatlines toward this point and a sharp distortion of the lines in its neighbourhood. As $y$ increases, the temperature profile flattens until the temperature is uniform in the $x$-direction for $y>2 \mathrm{~mm}$. Then, the alternation between the fin and the groove does not have any influence and the temperature field in the wick in contact with the liquid bulk of the reservoir is uniform.

As defined in Equation 13, the difference between the groove temperature and the reservoir temperature is set only by the pressure losses in the transport lines, the hydrostatic pressure difference and the non-condensable gases partial pressure. Smooth tubes with a relatively large diameter lead to reduced pressure losses. Therefore, the LHP operates with a groove temperature and a reservoir temperature almost equal. As a consequence, the convective cooling due to the liquid flow in the wick is extremely low and heat transfer in the porous structure is mainly controlled by heat conduction.

Figure 8 shows the effect of non-condensable gases on the evaporator temperature. Various quantities of air ranging between $1 \mu \mathrm{g}$ and $200 \mu \mathrm{g}$ are simulated in the reservoir. For a NCG mass below $10 \mu \mathrm{g}$, corresponding to a partial pressure $P_{\mathrm{NCG}}$ equal to about $400 \mathrm{~Pa}$, NCG do not have a determinant influence on the evaporator temperature. However, when the mass of NCG in the LHP is larger, its partial pressure is more important than the sum 


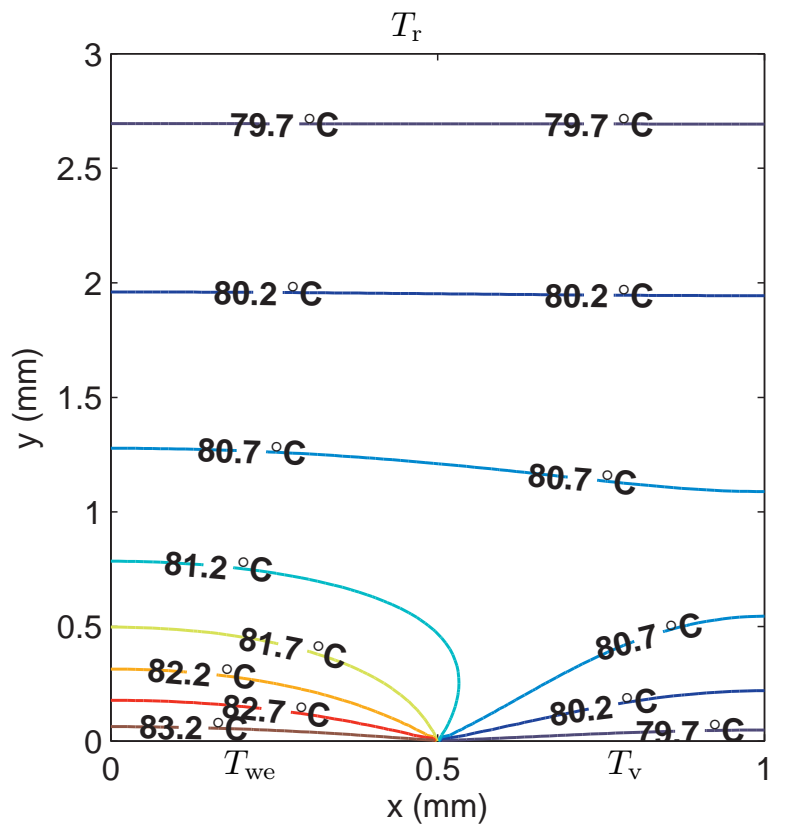

Figure 7: 2-D temperature field in the wick

of the pressure drops in the whole loop. The influence of NCG becomes then important at low heat input, leading to a significant increase of the evaporator temperature. As a consequence, the shape of the characteristic curve of the LHP is flattened.

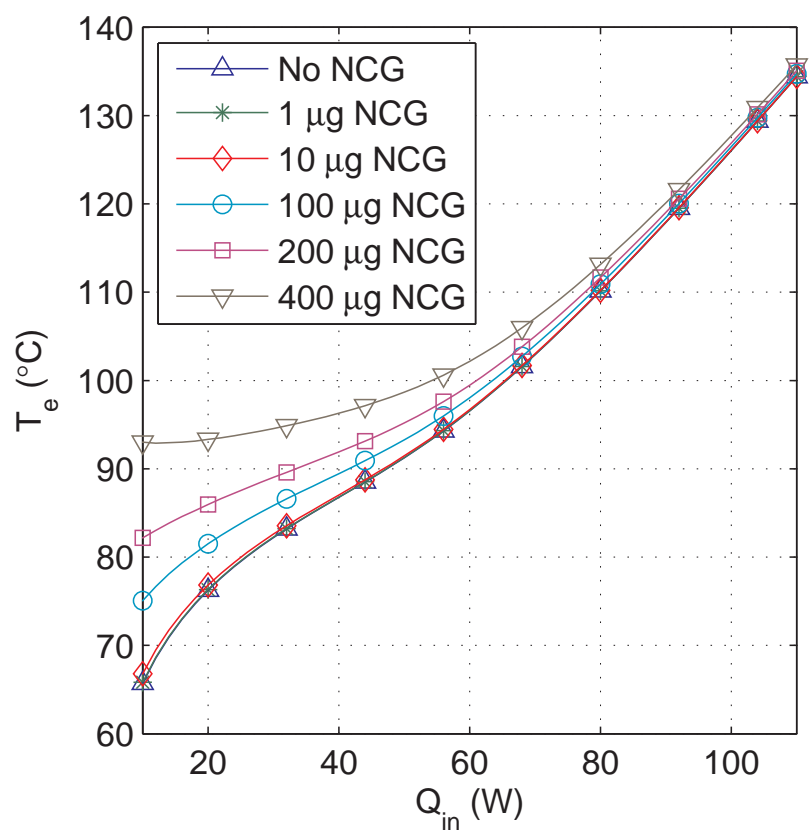

Figure 8: Influence of the NCGs on the evaporator temperature

These results are in accordance with Singh et al.'s experimental study [13]. Their work shows that the net effect of the generated NCG in the LHP was to produce an overall rise in the steady-state operating temperature. Besides, it was observed that the performance degrading effect of the NCG was more pronounced at low heat loads.

\subsection{Sensitivity analysis}

The LHP operation depends on many distinct parameters: the geometrical design (size, shape) of the system, the thermophysical properties of the working fluid and of the materials of the loop elements, the heat transfer characteristics inside and outside the LHP and the pressure losses in the system. Most of these parameters are easy to determine if the LHP geometry and the working fluid properties are known. However, some parameters are very difficult to determine precisely theoretically as it has been seen in the previous section: the effective thermal conductivity of the wick $\lambda_{\text {eff }}$, the contact resistance between the wick and the evaporator envelope $R_{\mathrm{c}}$ and the accommodation coefficient $a_{\mathrm{ev}}$. Furthermore, the heat sink heat transfer coefficient $h_{\text {sink }}$ and the heat transfer coefficient with the ambient $h_{\text {ext }}$ are also calculated using correlation being inherently inaccurate. Thus, in the present section, a sensitivity analysis is conducted on these parameters to see their influence on the model.

The sensitivity coefficient of the function $T=$ $f\left(x_{\mathrm{i}}, x_{\mathrm{j}}, x_{\mathrm{k}}, \ldots\right)$ in relation to the parameter $x_{\mathrm{i}}$ is defined as:

$$
S_{\mathrm{i}}=\left.\frac{\partial T}{\partial x_{\mathrm{i}}}\right|_{x_{\mathrm{j}}, x_{\mathrm{k}}, \ldots}
$$

In order to compare several parameter sensitivities, it is convenient to define relative sensitivities:

$$
S_{\mathrm{i}}^{*}=x_{\mathrm{i}} S_{\mathrm{i}}=\left.x_{\mathrm{i}} \frac{\partial T}{\partial x_{\mathrm{i}}}\right|_{x_{\mathrm{j}}, x_{\mathrm{k}}, \ldots}
$$

This coefficient enables to quantify the variation $\Delta T$ caused by a relative variation $\Delta x_{\mathrm{i}} / x_{\mathrm{i}}$ of the parameter $x_{\mathrm{i}}$. The greater the absolute value of the coefficient, the more the function is sensitive to the parameter.

Unless otherwise mentioned, the sensitivity analysis is conducted with the standard LHP defined in Table 1. A slight variation $(5 \%)$ of each studied parameter is applied, the value of the other parameters being constant. This effect on the temperatures at different locations of the LHP is predicted by the model.

Figure 9 presents the relative sensitivity of $T_{\mathrm{e}}, T_{\mathrm{v}}, T_{\mathrm{r}, \text { in }}$ and $T_{\mathrm{c}, \mathrm{o}}$ to the heat transfer coefficient with the ambient. Sensitivities of $T_{\mathrm{e}}$ and $T_{\mathrm{v}}$ are significant for low heat inputs and decrease with the heat load. Heat transfer with the ambient cools the loop down and leads to a lower operational temperature. As expected, $h_{\text {ext }}$ does not have any influence on $T_{\mathrm{r}, \mathrm{i}}$ and $T_{\mathrm{c}, \mathrm{o}}$ in variable conductance mode because their value is only set by the heat sink. For higher heat loads, the increase of the heat losses to the ambient lead to a lower operational temperature. As a consequence, a larger part of the condenser is used to condensate the vapour, the subcooling length in the condenser is smaller and $T_{\mathrm{c}, \mathrm{o}}$ increases. The same effect is observed on 
$T_{\mathrm{r}, \text { in }}$, but partially offset by the heat losses from the liquid line to the ambient.

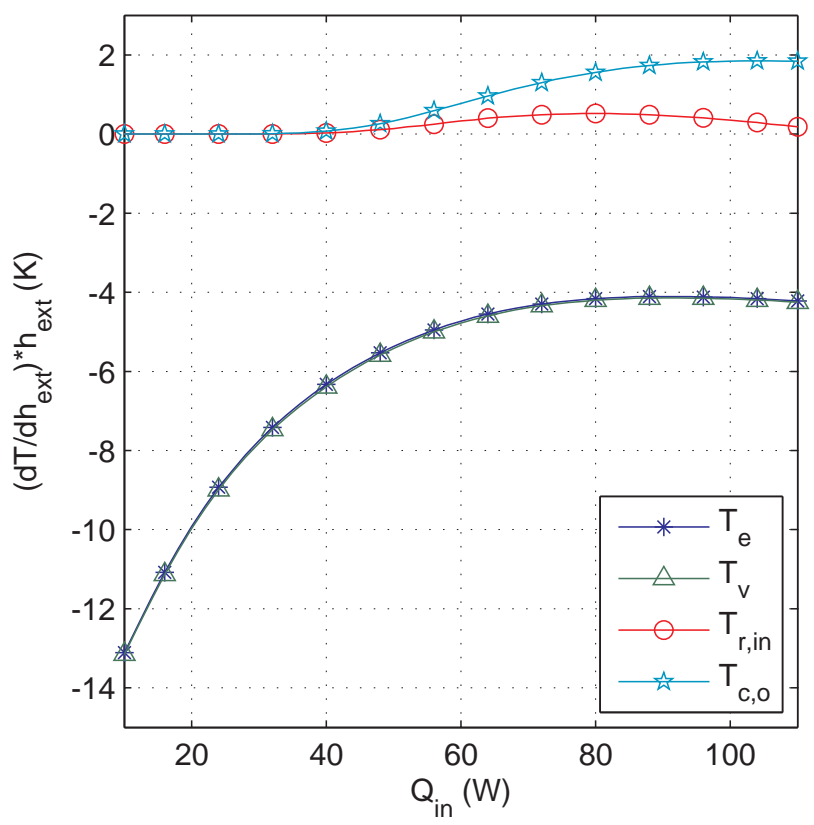

Figure 9: Relative sensitivity of the LHP temperatures to $h_{\text {ext }}$

In many experimental configurations, an adequate thermal insulation of the entire LHP enables to reduce considerably the heat losses to the ambient. In the following, this parameter is set to zero in order to better highlight the effect of the other parameters on the LHP.

The relative sensitivity of the vapour temperature to the other parameters is shown in Figure 10. It is clear that heat transfer inside the evaporator (function of the parameters $\lambda_{\text {eff }}, R_{\mathrm{c}}$ and $a_{\mathrm{ev}}$ ) governs the operation in variable conductance mode whereas at high heat loads, $h_{\text {sink }}$ becomes the dominant parameter. Indeed, at low heat loads, $T_{\text {c,o }}$ equals $T_{\text {sink }}$ so the heat transfer coefficient with the heat sink has no influence on the subcooling of the liquid and on the LHP operation in general. In fixed conductance mode, heat transfer in the condenser sets the LHP operational temperature and the sensitivity of $T_{\mathrm{v}}$ to $h_{\text {sink }}$ is linear. The parameters $a_{\text {ev }}, \lambda_{\text {eff }}$ and $R_{\mathrm{c}}$ have a moderate influence on the vapour temperature and this influence decreases as the heat load increases.

The relative sensitivity of $T_{\mathrm{e}}$ to the same parameters is shown in Figure 11. The influence of the accommodation coefficient and of the heat transfer with the heat sink is almost the same as for $T_{\mathrm{v}}$. However, the sensitivities to $R_{\mathrm{c}}$ and $\lambda_{\text {eff }}$ have a different behaviour. While the contact resistance has a limited effect on $T_{\mathrm{v}}$, its influence on $T_{\mathrm{e}}$ is large and increases with the heat input. Indeed, the difference between $T_{\mathrm{e}}$ and $T_{\mathrm{we}}$ is proportional to the heat transfer rate $Q_{\mathrm{w}}$ and to $R_{\mathrm{c}}$. As the heat input $Q_{\text {in }}$ increases, $Q_{\mathrm{w}}$ increases almost linearly and leads to a higher sensitivity of $T_{\mathrm{e}}$ to the contact resistance.

The particular shape of the relative sensitivity of $T_{\mathrm{e}}$ to

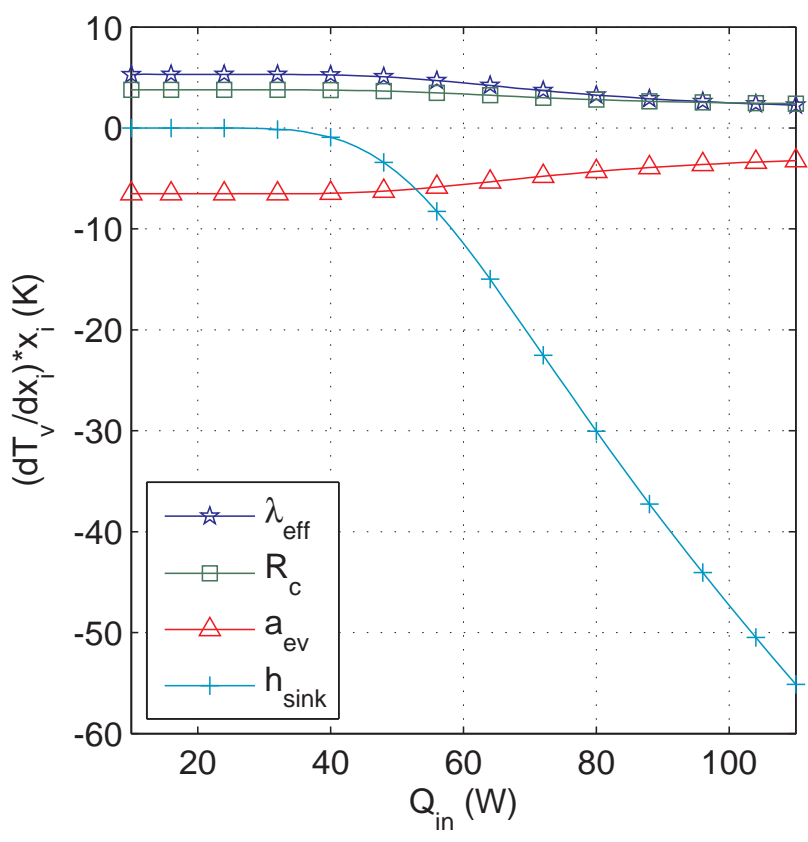

Figure 10: Relative sensitivity of $T_{\mathrm{v}}$ to various parameters

$\lambda_{\text {eff }}$ is discussed in the following; it requires a more detailed analysis on the effect of $\lambda_{\text {eff }}$ on the LHP thermal behaviour.

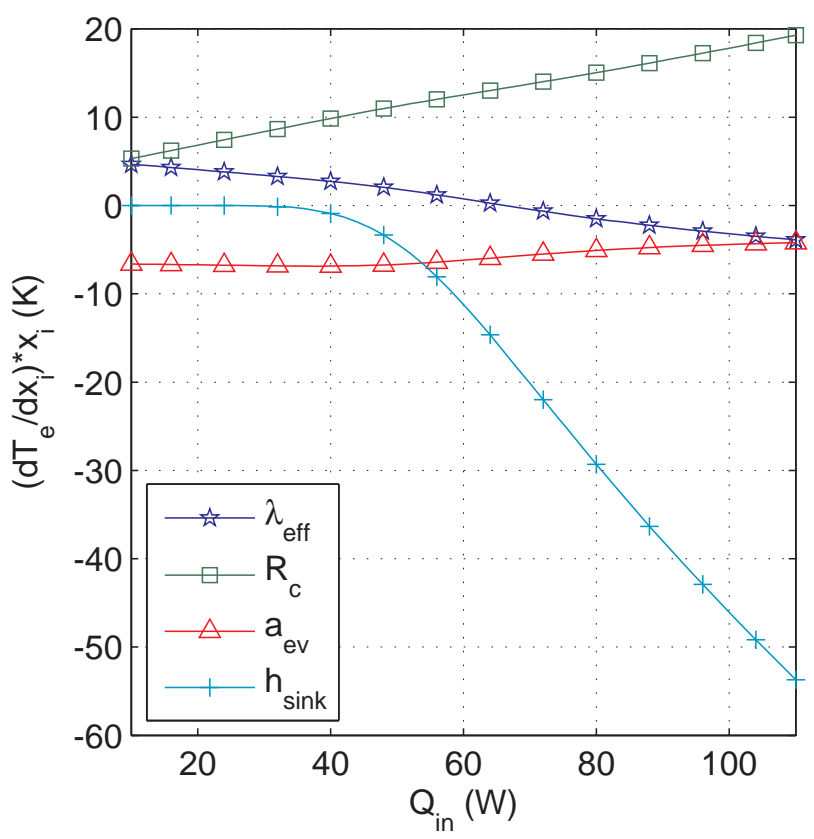

Figure 11: Relative sensitivity of $T_{\mathrm{e}}$ to various parameters

Figure 12 shows the variation of the vapour temperature with the effective thermal conductivity of the wick for several heat loads. An optimal value of $\lambda_{\text {eff }}$ is found between 1 and $2 \mathrm{~W} \cdot \mathrm{m}^{-1} \cdot \mathrm{K}^{-1}$ whatever the heat input. This minimum value of $T_{\mathrm{v}}$ is a consequence of the evolution of the heat transferred from the casing to the evaporation zone. As the thermal conductivity of the wick increases, 
the heat entering the wick becomes larger at the expense of the longitudinal parasitic heat flux. Figure 13 shows the distribution of heat transfer in the evaporator. The largest part of the heat load $Q_{\text {in }}$ enters the wick $\left(Q_{\mathrm{w}}\right)$, whereas the rest is thermally conducted through the evaporator body $\left(Q_{\mathrm{b}}\right)$. When the value of $\lambda_{\text {eff }}$ is very low, increasing the conductivity enhances both the evaporation $\left(Q_{\mathrm{ev}}\right)$ and the transversal parasitic heat flux $\left(Q_{\mathrm{w}}-Q_{\mathrm{ev}}\right)$. When $\lambda_{\text {eff }}$ exceeds $1 \mathrm{~W} \cdot \mathrm{m}^{-1} \cdot \mathrm{K}^{-1}$, the increase of the heat flux entering the wick $Q_{\mathrm{w}}$ is smaller, leading to an increase of the transversal parasitic heat flux at the expense of $Q_{\mathrm{ev}}$, that decreases as $\lambda_{\text {eff }}$ becomes larger. The maximum evaporation heat flux leads to a minimum vapour temperature (Figure 12). The same conclusion has been drawn in the numerical study of Siedel et al.[15].

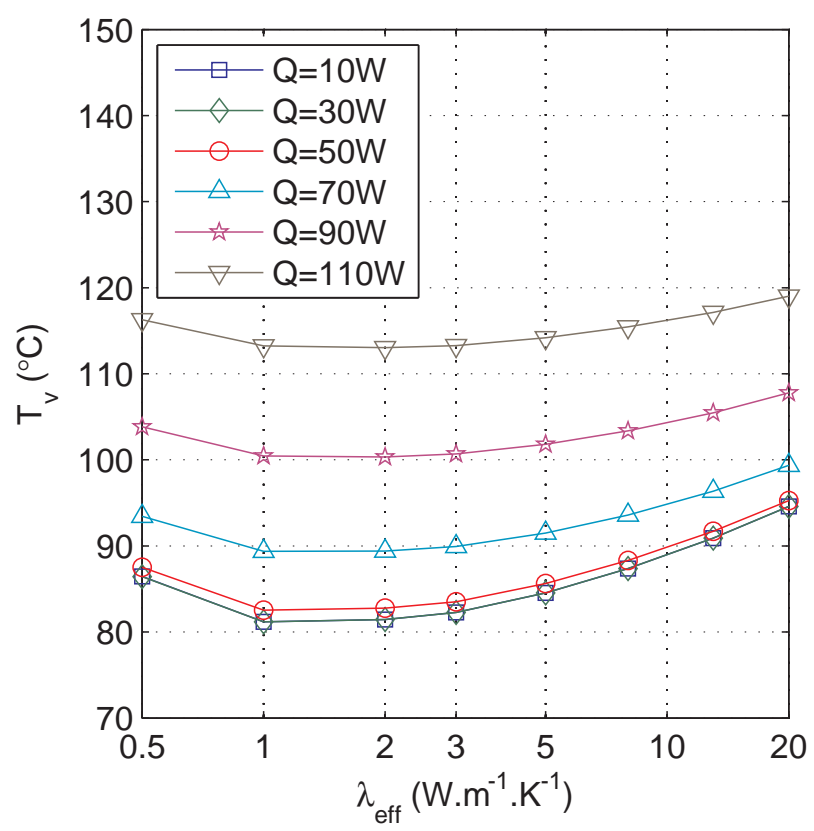

Figure 12: Influence of $\lambda_{\text {eff }}$ on $T_{\mathrm{v}}$

The evolution of the temperature difference $T_{\mathrm{e}}-T_{\mathrm{v}}$ with $\lambda_{\text {eff }}$ for several heat inputs is given in Figure 14. As expected, this difference decreases when the thermal conductivity of the wick increases. Indeed, a higher value of

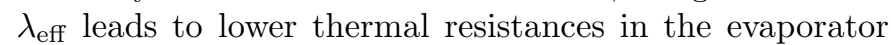
(Figure 1). Figure 15 presents the evolution of $T_{\mathrm{e}}$ with $\lambda_{\text {eff }}$, which is a consequence of the results obtained in figures 12 and 14. An optimal effective thermal conductivity exists, for which $T_{\mathrm{e}}$ is minimal. However, its value is also dependent on the heat input $Q_{\text {in }}$, contrary to the temperature of the vapour (Figure 12). The optimal value of $\lambda_{\text {eff }}$ (obtained for the minimum value of $T_{\mathrm{e}}$ ) increases from $2 \mathrm{~W} \cdot \mathrm{m}^{-1} \cdot \mathrm{K}^{-1}$ to $10 \mathrm{~W} \cdot \mathrm{m}^{-1} \cdot \mathrm{K}^{-1}$ with the increase of the heat input from $10 \mathrm{~W}$ to $110 \mathrm{~W}$. Therefore, there is not an optimal value of the thermal conductivity of the wick but a range of optimal values depending on the heat load.

Figure 15 shows that at a given $\lambda_{\text {eff }}$ (for example

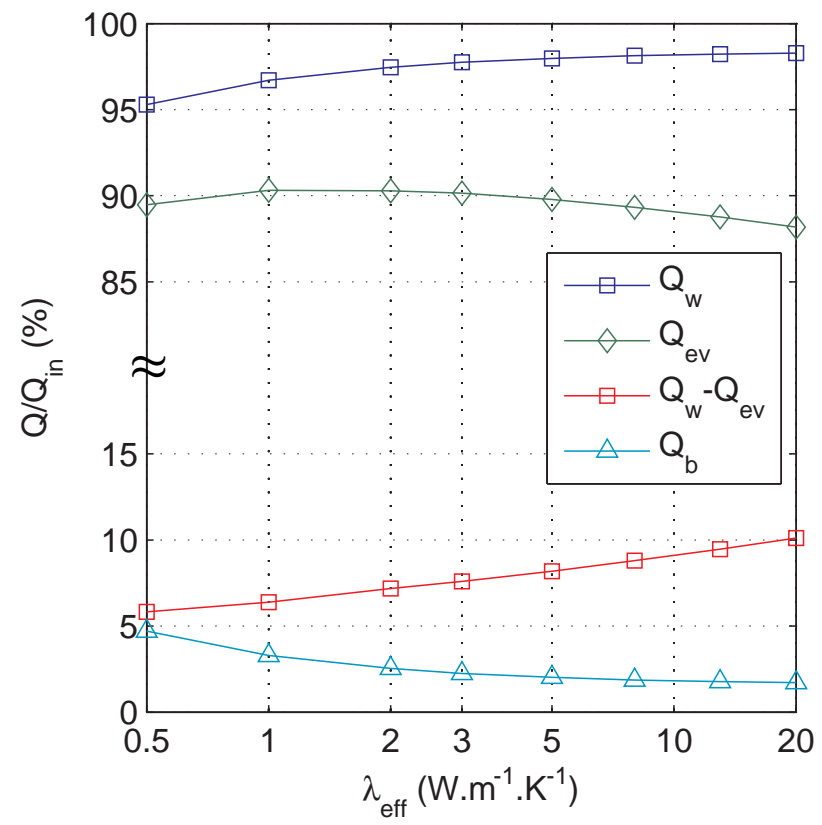

Figure 13: Distribution of heat transfer in the evaporator $\left(Q_{\text {in }}=\right.$ $50 \mathrm{~W})$

$5 \mathrm{~W} \cdot \mathrm{m}^{-1} \cdot \mathrm{K}^{-1}$ in the standard case), the sign of the slope of the temperature curve changes as the heat flux increases. As a consequence, the sign of the sensitivity of $T_{\mathrm{e}}$ to $\lambda_{\text {eff }}$ changes when increasing the heat load, as it is shown in Figure 11. This is not the case for $T_{\mathrm{v}}$, since the minimum of the curves $T_{\mathrm{v}}\left(\lambda_{\text {eff }}\right)$ does not depend on the heat flux (Figure 12).

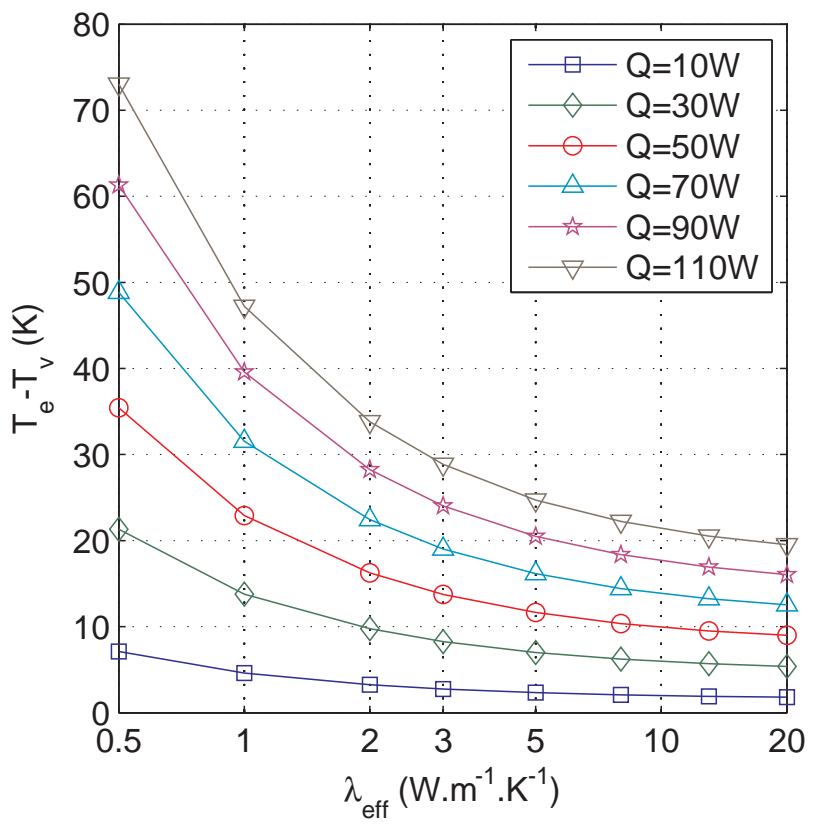

Figure 14: Influence of $\lambda_{\text {eff }}$ on $T_{\mathrm{e}}-T_{\mathrm{v}}$

This sensitivity analysis shows that the main parameters of the model are independent. Therefore, their in- 


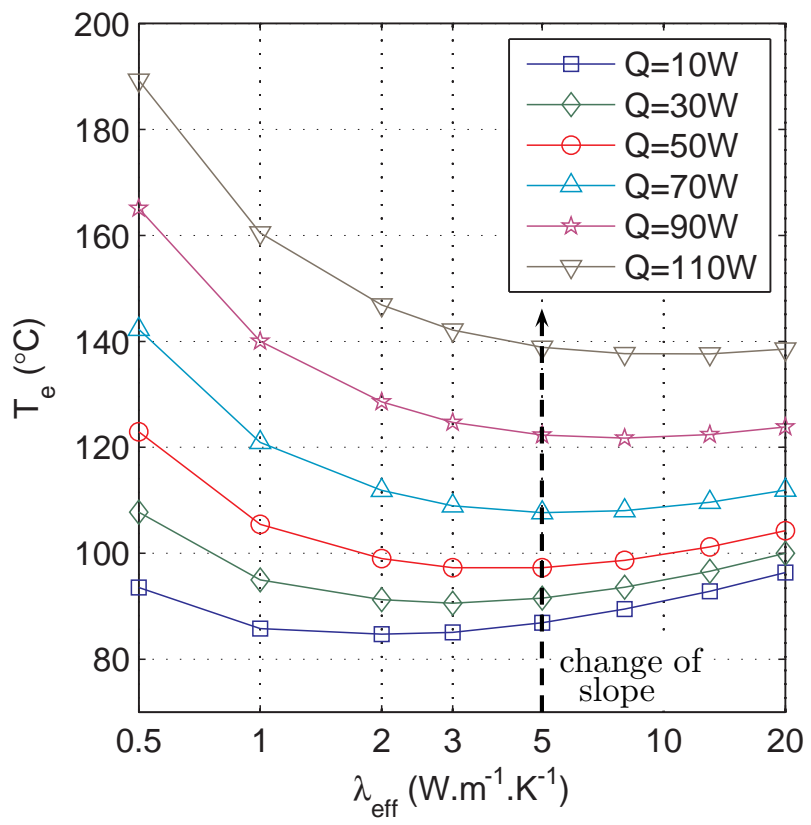

Figure 15: Influence of $\lambda_{\text {eff }}$ on $T_{\mathrm{e}}$

fluence can be differentiated from each other. Thus, the availability of precise experimental data of several representative temperatures of the LHP for various heat inputs may theoretically lead to a precise determination of these parameters and provide the model with adequate input parameters. This sensitivity analysis also shows the large influence of the tested parameters on the LHP operation. Their inaccurate determination can lead to a major error on the LHP operation prediction.

\subsection{Model validation}

The present analytical model is compared to an experimental data set from Singh et al. [19] for a validation purpose. These authors studied the operational characteristics of a flat disk-shaped evaporator LHP, $30 \mathrm{~mm}$ in diameter, using water as working fluid. The $3 \mathrm{~mm}$ thick porous wick is made of sintered nickel and its thermal effective conductivity is considered equal to about $5.87 \mathrm{~W} \cdot \mathrm{m}^{-1} \cdot \mathrm{K}^{-1}$ using Alexander's formula and based on Singh et al.'s study[22]:

$$
\lambda_{\mathrm{eff}}=\lambda_{\mathrm{l}}\left(\frac{\lambda_{\mathrm{l}}}{\lambda_{\mathrm{wm}}}\right)^{-(1-\varepsilon)^{0.59}}
$$

where $\lambda_{\mathrm{l}}$ and $\lambda_{\mathrm{wm}}$ are the thermal conductivities of the liquid and of the wick material respectively and $\varepsilon$ is the porosity, equal to $75 \%$. The wick is embedded in a copper evaporator. The vapour and liquid lines, of internal diameter $2 \mathrm{~mm}$, are $150 \mathrm{~mm}$ and $290 \mathrm{~mm}$ long respectively. A finand-tube condenser, $50 \mathrm{~mm}$ long, dissipates heat by forced convection of air at ambient temperature (i.e. $22^{\circ} \mathrm{C}$ ). No parasitic heat transfer through the evaporator body is taken into account, since an O-ring seal prevents heat conduction to the reservoir. Figure 16 shows the comparison between the experimental results and the calculated temperatures of the evaporator wall and of the vapour in the grooves. A good agreement is found between the experimental data and the model. Several unknown parameters were identified by comparison of the predicted values with the experimental data of Singh et al.: the heat transfer coefficient between the condenser wall and the heat sink, the evaporator wall thickness, the contact resistance and the accommodation coefficient. As a result, a straight-tube equivalent condenser is simulated with a heat transfer coefficient $h_{\text {sink }}$ fixed to $3.2 \mathrm{~kW} \cdot \mathrm{m}^{-2} \cdot \mathrm{K}^{-1}$, considering an outside diameter of $2.4 \mathrm{~mm}$ for the tubes. The accommodation coefficient is equal to 0.4 . The value of $R_{\mathrm{c}}$ is set to $10^{-5} \mathrm{~K} \cdot \mathrm{m}^{2} \cdot \mathrm{W}^{-1}$. The value of $R_{\mathrm{c}}$ that enables to fit at best the results is very small, but it has to be noted that $T_{\mathrm{v}}$ is not really the experimental measurement of the vapour temperature, but the temperature of the tube at the exit of the evaporator. Therefore, these experimental results are not sufficient to estimate accurately the parameters. Nevertheless, the order of magnitude of the parameters are close to the one defined for the standard case.

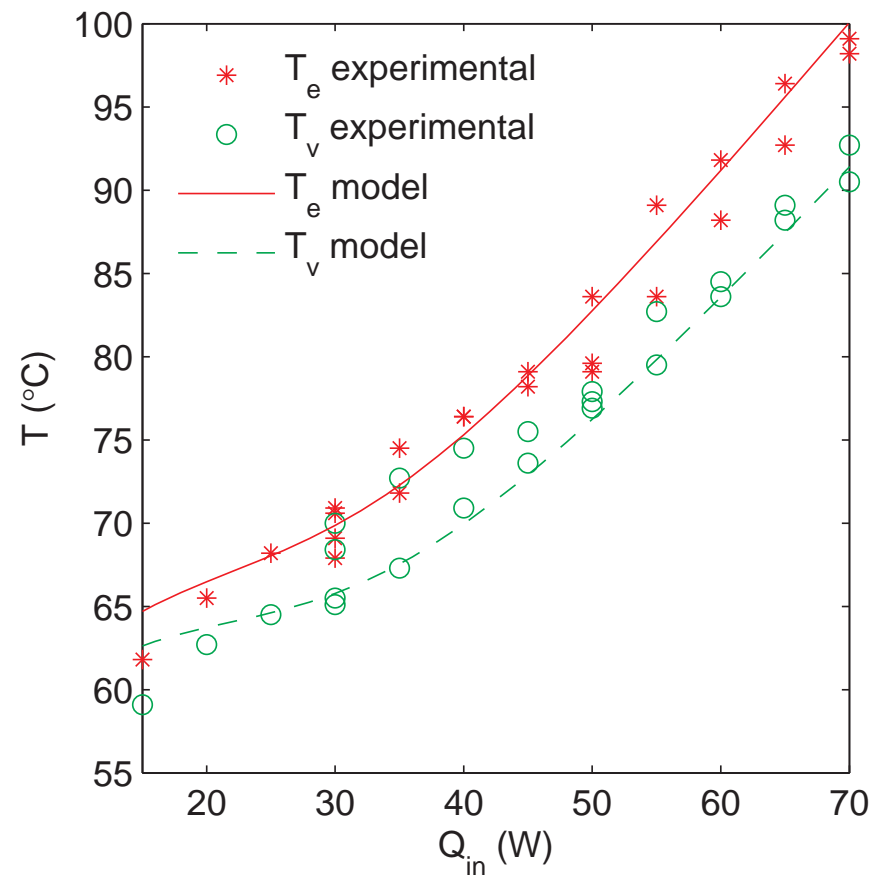

Figure 16: Comparison between the model and data from Singh et al. [19]

\section{Conclusion}

In this paper, a complete analytical model of a LHP has been developed. Its originality lies in the combination of energy balance equations for each component of the system with analytical solutions for the temperature field in the evaporator. Based on Fourier series expansions, heat transfer in the wick as well as in the evaporator casing are 
accurately modelled. This analytical method offers a simple solution that can be implemented in LHP design analysis without the need of large computational resources.

A sensitivity analysis has been undertaken to assess the influence of five parameters on the loop operation. This analysis enables a better comprehension of the operating mechanisms of the LHP as well as a comparative study of the parameters affecting its temperatures. It appears that these parameters can be experimentally determined using an appropriate test bench with only few temperature measurements.

This model has been validated with a set of experimental data from the literature. A good agreement has been met between the simulation and the experimental results.

The model results show that convection inside the wick does not play a major role and can be neglected. Moreover, the temperature field in the wick is almost uniform far from the grooves.

In accordance with experimental data from the literature, the presence of NCGs in the reservoir leads to an increase of the evaporator temperature. This degrading effect is more pronounced at low heat loads.

\section{Nomenclature}

\begin{tabular}{|c|c|c|}
\hline$A$ & $\begin{array}{l}\text { Fourier series coefficient } \\
\text { cross-sectional area }\end{array}$ & {$\left[m^{2}\right]$} \\
\hline$a, a_{0}, a_{1}$ & length & {$[m]$} \\
\hline$a_{\mathrm{ev}}$ & accommodation coefficient & \\
\hline$B$ & length ratio & \\
\hline & Fourier series coefficient & \\
\hline$b$ & length & {$[m]$} \\
\hline$C$ & Fourier series coefficient & \\
\hline$c, c_{0}, c_{1}$ & length & {$[m]$} \\
\hline$c_{\mathrm{p}}$ & specific heat & {$\left[J \cdot k g^{-1} \cdot K^{-1}\right]$} \\
\hline$D$ & $\begin{array}{l}\text { diameter } \\
\text { length ratio }\end{array}$ & {$[m]$} \\
\hline$d$ & length & {$[m]$} \\
\hline$e$ & thickness & {$[m]$} \\
\hline$f$ & friction factor & \\
\hline$g$ & gravitational acceleration & {$\left[m . s^{-2}\right]$} \\
\hline$H$ & height & {$[m]$} \\
\hline$h$ & heat transfer coefficient & {$\left[W \cdot m^{-2} \cdot K^{-1}\right]$} \\
\hline $\begin{array}{l}h_{\mathrm{lv}} \\
K\end{array}$ & $\begin{array}{l}\text { enthalpy of vaporization } \\
\text { coefficient }\end{array}$ & {$\left[J . k g^{-1}\right]$} \\
\hline$L$ & length & {$[m]$} \\
\hline$M$ & molar mass & {$\left[\mathrm{kg}^{\mathrm{m}} \mathrm{mol}^{-1}\right]$} \\
\hline$m, n$ & Fourier series increment & \\
\hline$m_{\mathrm{f}}$ & total fluid charge & {$[k g]$} \\
\hline$\dot{m}$ & mass flow rate & {$\left[\mathrm{kg} . \mathrm{s}^{-1}\right]$} \\
\hline$P$ & pressure & {$[\mathrm{Pa}]$} \\
\hline$Q$ & heat transfer rate & {$[W]$} \\
\hline$q$ & volumetric heat source & {$\left[W \cdot m^{-3}\right]$} \\
\hline
\end{tabular}

$\begin{array}{lll}R_{\mathrm{c}} & \text { contact resistance } & {\left[\mathrm{K} \cdot \mathrm{m}^{2} \cdot \mathrm{W}^{-1}\right]} \\ S & \text { surface area } & {\left[\mathrm{m}^{2}\right]} \\ S_{\mathrm{i}} & \text { absolute sensitivity } & \\ S_{\mathrm{i}}^{*} & \text { relative sensitivity } & \\ T & \text { temperature } & {[\mathrm{K}]} \\ T^{*} & \text { non-dimensional temperature } & \\ V & \text { volume } & {\left[\mathrm{m}^{3}\right]} \\ X, Y & \text { non-dimensional coordinates } & \\ x_{\mathrm{i}, \mathrm{j}, \mathrm{k}} & \text { sensitivity parameter } & \\ x, y & \text { axis coordinates } & {[\mathrm{m}]}\end{array}$

\section{Greek Symbols}

$\Delta \quad$ difference

$\varepsilon \quad$ porosity

$\lambda \quad$ thermal conductivity $\left[W \cdot m^{-1} \cdot K^{-1}\right]$

$\phi, \phi_{0}$ heat flux $\quad\left[W . m^{-2}\right]$

$\rho$ density $\quad\left[\mathrm{kg} \cdot \mathrm{m}^{-3}\right]$

\section{Subscripts}

$\begin{array}{ll}2 \phi & \text { two-phase } \\ \text { air } & \text { air } \\ \text { b } & \text { evaporator body } \\ \text { c } & \text { condenser, convective, contact } \\ \text { e } & \text { evaporator } \\ \text { eff } & \text { effective } \\ \text { ev } & \text { evaporation } \\ \text { ext } & \text { external, ambient } \\ \text { i } & \text { inner } \\ \text { in } & \text { input, inlet } \\ \text { l } & \text { liquid } \\ \text { NCG } & \text { non condensable gas } \\ \text { o } & \text { outlet, outer } \\ \text { r } & \text { reservoir } \\ \text { sen } & \text { sensible } \\ \text { sink } & \text { heat sink } \\ \text { sub } & \text { subcooling } \\ \text { t } & \text { total (including convection) } \\ \text { v } & \text { vapour } \\ \text { w } & \text { wick } \\ \text { we } & \text { wick side of the wick-envelope interface } \\ \text { wm } & \text { wick material } \\ & \end{array}$

\section{Non Dimensional Numbers}

$B i \quad$ Biot number

Pr Prandtl number

$R a$ Rayleigh number

Re Reynolds number

\section{References}

[1] Y. F. Maydanik, Miniature loop heat pipes, in: $13^{\text {th }}$ International Heat Pipe Conference, 2004, pp. 23-35.

[2] Y. Maydanik, Loop heat pipes, Applied Thermal Engineering 25 (2005) 635-657. 
[3] T. Kaya, J. Ku, T. T. Hoang, M. K. Cheung, Mathematical modeling of loop heat pipes, in: $37^{\text {th }}$ AIAA Aerospace Sciences Meeting and Exhibit, 1999.

[4] A. Delil, V. Baturkin, G. Gorbenko, P. Gakal, V. Ruzaykin, Modelling of a miniature loop heat pipe with a flat evaporator, in: Proceedings of the $32^{\text {nd }}$ International Conference on Environmental Systems, 2002.

[5] P. Chuang, An improved steady-state model of loop heat pipes based on experimental and theoretical analyses, Ph.D. thesis, Pennsylvania State University (2003).

[6] L. Bai, G. Lin, H. Zhang, D. Wen, Mathematical modeling of steady-state operation of a loop heat pipe, Applied Thermal Engineering 29 (2009) 2643-2654.

[7] Y. F. Maydanik, Y. G. Fershtater, N. N. Solodovnik, Loop heat pipes: Design, investigation, prospects of use in aerospace technics, Tech. Rep. 941185, SAE International, Warrendale, PA (Apr. 1994)

[8] S. Launay, V. Sartre, J. Bonjour, Analytical model for characterization of loop heat pipes, Journal of Thermophysics and Heat Transfer 22 (4) (2008) 623-631.

[9] M. Furukawa, Model-based method of theoretical design analysis of a loop heat pipe, Journal of Thermophysics and Heat Transfer 20 (1) (2006) 111-121.

[10] F. Lefèvre, M. Lallemand, Coupled thermal and hydrodynamic models of flat micro heat pipes for the cooling of multiple electronic components, International Journal of Heat and Mass Transfer 49 (7-8) (2006) 1375-1383.

[11] S. Lips, F. Lefèvre, A general analytical model for the design of conventional heat pipes, to be published, International Journal of Heat and Mass Transfer.

[12] A. Adoni, A. Ambirajan, V. Jasvanth, D. Kumar, P. Dutta, Theoretical studies of hard filling in loop heat pipes, Journal of Thermophysics and Heat Transfer 24 (1) (2010) 173-183.

[13] R. Singh, A. Akbarzadeh, M. Mochizuki, Operational characteristics of the miniature loop heat pipe with non-condensable gases, International Journal of Heat and Mass Transfer 53 (17) (2010) 3471-3482.

[14] V. P. Carey, Liquid-vapor phase-change phenomena, Hemisphere, New York, 1992.

[15] B. Siedel, V. Sartre, F. Lefèvre, Numerical investigation of the thermohydraulic behaviour of a complete loop heat pipe, Applied Thermal Engineering 61 (2) (2013) 541-553.

[16] I. Eames, N. Marr, H. Sabir, The evaporation coefficient of water: a review, International Journal of Heat and Mass Transfer 40 (12) (1997) 2963-2973.

[17] Y. Cao, A. Faghri, Analytical solutions of flow and heat transfer in a porous structure with partial heating and evaporation on the upper surface, International Journal of Heat and Mass Transfer 37 (10) (1994) 1525-1533.

[18] F. P. Incropera, D. P. DeWitt, Fundamentals of heat and mass transfer, John Wiley \& Sons, 1996.

[19] R. Singh, A. Akbarzadeh, M. Mochizuki, Operational characteristics of a miniature loop heat pipe with flat evaporator, International Journal of Thermal Sciences 47 (2008) 1504-1515.

[20] J. Choi, B. Sung, C. Kim, D.-A. Borca-Tasciuc, Interface engineering to enhance thermal contact conductance of evaporators in miniature loop heat pipe systems, Applied Thermal Engineering 60 (1-2) (2013) 371-378.

[21] S. Mo, P. Hu, J. Cao, Z. Chen, H. Fan, F. Yu, Effective thermal conductivity of moist porous sintered nickel material, International Journal of Thermophysics 27 (1) (2006) 304-313.

[22] R. Singh, A. Akbarzadeh, M. Mochizuki, Effect of wick characteristics on the thermal performance of the miniature loop heat pipe, Journal of Heat Transfer 131 (8) (2009) 082601.

[23] K. Boomsma, D. Poulikakos, On the effective thermal conductivity of a three-dimensionally structured fluid-saturated metal foam, International Journal of Heat and Mass Transfer 44 (4) (2001) 827-836.

[24] C. Li, G. P. Peterson, The effective thermal conductivity of wire screen, International Journal of Heat and Mass Transfer 49 (21-22) (2006) 4095-4105. 


\section{Appendix A. Detailed expression of the K-coefficients}

$$
\begin{aligned}
& K_{1}=S_{\mathrm{w}} \frac{a_{0}+a_{1}}{2 a}\left(-\frac{\lambda_{\mathrm{eff}}}{b}+\dot{m}_{\mathrm{l}} c_{\mathrm{p}, 1} \frac{6}{\pi D_{\mathrm{w}}^{2}}\right) \\
& K_{2}=S_{\mathrm{w}}\left[\sum_{m=1}^{\infty} 2 \frac{\lambda_{\mathrm{eff}}}{a_{1}-a_{0}} \frac{1}{m^{2} \pi^{2}} \sin \left(m \pi \frac{a_{0}+a_{1}}{2 a}\right)\left(\cos \left(\frac{m \pi a_{0}}{a}\right)-\cos \left(\frac{m \pi a_{1}}{a}\right)\right)\left(\left(1-e^{2 m \pi B}\right)^{-1}-\left(1-e^{-2 m \pi B}\right)^{-1}\right)\right. \\
& \left.+\frac{a_{0}+a_{1}}{2 a}\left(\frac{\lambda_{\mathrm{eff}}}{b}\left(1-\frac{a_{0}+a_{1}}{2 a}\right)-\dot{m}_{1} c_{\mathrm{p}, \mathrm{l}} \frac{6}{\pi D_{\mathrm{w}}^{2}}\right)\right] \\
& K_{3}=-S_{\mathrm{w}}\left[\sum_{m=1}^{\infty} 2 \frac{\lambda_{\mathrm{eff}}}{a_{1}-a_{0}} \frac{1}{m^{2} \pi^{2}} \sin \left(m \pi \frac{a_{0}+a_{1}}{2 a}\right)\left(\cos \left(\frac{m \pi a_{0}}{a}\right)-\cos \left(\frac{m \pi a_{1}}{a}\right)\right)\left(\left(1-e^{2 m \pi B}\right)^{-1}-\left(1-e^{-2 m \pi B}\right)^{-1}\right)\right. \\
& \left.-\frac{\lambda_{\text {eff }}}{b}\left(\frac{a_{0}+a_{1}}{2 a}\right)^{2}\right] \\
& K_{4}=S_{\mathrm{w}}\left(1-\frac{a_{0}+a_{1}}{2 a}\right)\left(\frac{\lambda_{\mathrm{eff}}}{b}-\dot{m}_{\mathrm{l}} c_{\mathrm{p}, \mathrm{l}} \frac{6}{\pi D_{\mathrm{w}}^{2}}\right) \\
& K_{5}=S_{\mathrm{w}}\left[\sum_{m=1}^{\infty} 2 \frac{\lambda_{\text {eff }}}{a_{1}-a_{0}} \frac{1}{m^{2} \pi^{2}} \sin \left(m \pi \frac{a_{0}+a_{1}}{2 a}\right)\left(\cos \left(\frac{m \pi a_{0}}{a}\right)-\cos \left(\frac{m \pi a_{1}}{a}\right)\right)\left(\left(1-e^{2 m \pi B}\right)^{-1}-\left(1-e^{-2 m \pi B}\right)^{-1}\right)\right. \\
& \left.-\left(1-\frac{a_{0}+a_{1}}{2 a}\right)\left(\frac{\lambda_{\mathrm{eff}}}{b}\left(1-\frac{a_{0}+a_{1}}{2 a}\right)-\dot{m}_{1} c_{\mathrm{p}, 1} \frac{6}{\pi D_{\mathrm{w}}^{2}}\right)\right] \\
& K_{6}=-S_{\mathrm{w}}\left[\sum_{m=1}^{\infty} 2 \frac{\lambda_{\mathrm{eff}}}{a_{1}-a_{0}} \frac{1}{m^{2} \pi^{2}} \sin \left(m \pi \frac{a_{0}+a_{1}}{2 a}\right)\left(\cos \left(\frac{m \pi a_{0}}{a}\right)-\cos \left(\frac{m \pi a_{1}}{a}\right)\right)\left(\left(1-e^{2 m \pi B}\right)^{-1}-\left(1-e^{-2 m \pi B}\right)^{-1}\right)\right. \\
& \left.+\frac{\lambda_{\mathrm{eff}}}{b} \frac{a_{0}+a_{1}}{2 a}\left(1-\frac{a_{0}+a_{1}}{2 a}\right)\right] \\
& K_{7}=h_{\mathrm{ext}} \pi c_{0}\left(c_{1}-\frac{c_{0}}{2}\right)\left(\frac{-\frac{c_{0}+c_{1}}{2 c}+1}{B i_{\mathrm{b}}+1}\right) \\
& -\sum_{m=1}^{\infty}\left(2 \lambda_{\mathrm{b}} \frac{c}{c_{1}-c_{0}} \frac{1}{m^{2} \pi^{2}}\left(\cos \left(\frac{m \pi c_{0}}{c}\right)-\cos \left(\frac{m \pi c_{1}}{c}\right)\right)\right. \\
& {\left[\left(c_{0} \pi \sin \left(\frac{m \pi c_{1}}{c}\right)\left(e^{m \pi D}-1\right)+\frac{\pi h_{\mathrm{ext}}}{\lambda_{\mathrm{b}}} \frac{c}{m \pi}\left(\frac{c}{m \pi}\left(-1+\cos \left(\frac{m \pi c_{0}}{c}\right)\right)+c_{0} \sin \left(\frac{m \pi c_{1}}{c}\right)\right)\right)\right.} \\
& \left(e^{m \pi D}+e^{-m \pi D} \frac{m \pi D+B i_{\mathrm{b}}}{m \pi D-B i_{\mathrm{b}}}\right)^{-1} \\
& +\left(-c_{0} \pi \sin \left(\frac{m \pi c_{1}}{c}\right)\left(e^{-m \pi D}-1\right)+\frac{\pi h_{\mathrm{ext}}}{\lambda_{\mathrm{b}}} \frac{c}{m \pi}\left(\frac{c}{m \pi}\left(-1+\cos \left(\frac{m \pi c_{0}}{c}\right)\right)+c_{0} \sin \left(\frac{m \pi c_{1}}{c}\right)\right)\right) \\
& \left.\left.\left(e^{-m \pi D}+e^{+m \pi D} \frac{m \pi D-B i_{\mathrm{b}}}{m \pi D+B i_{\mathrm{b}}}\right)^{-1}\right]\right) \\
& K_{8}=h_{\mathrm{ext}} \pi c_{0}\left(c_{1}-\frac{c_{0}}{2}\right) \frac{c_{0}+c_{1}}{2 c} \frac{1}{B i_{\mathrm{b}}+1} \\
& +\sum_{m=1}^{\infty}\left(2 \lambda_{\mathrm{b}} \frac{c}{c_{1}-c_{0}} \frac{1}{m^{2} \pi^{2}}\left(\cos \left(\frac{m \pi c_{0}}{c}\right)-\cos \left(\frac{m \pi c_{1}}{c}\right)\right)\right. \\
& {\left[\left(c_{0} \pi \sin \left(\frac{m \pi c_{1}}{c}\right)\left(e^{m \pi D}-1\right)+\frac{\pi h_{\mathrm{ext}}}{\lambda_{\mathrm{b}}} \frac{c}{m \pi}\left(\frac{c}{m \pi}\left(-1+\cos \left(\frac{m \pi c_{0}}{c}\right)\right)+c_{0} \sin \left(\frac{m \pi c_{1}}{c}\right)\right)\right)\right.} \\
& \left(\left(e^{m \pi D}+e^{-m \pi D} \frac{m \pi D+B i_{\mathrm{b}}}{m \pi D-B i_{\mathrm{b}}}\right)^{-1}\right) \\
& +\left(c_{0} \pi \sin \left(\frac{m \pi c_{1}}{c}\right)\left(e^{-m \pi D}-1\right)+\frac{\pi h_{\mathrm{ext}}}{\lambda_{\mathrm{b}}} \frac{c}{m \pi}\left(\frac{c}{m \pi}\left(-1+\cos \left(\frac{m \pi c_{0}}{c}\right)\right)+c_{0} \sin \left(\frac{m \pi c_{1}}{c}\right)\right)\right)
\end{aligned}
$$




$$
\begin{aligned}
& \left.\left.\left(e^{-m \pi D}+e^{+m \pi D} \frac{m \pi D-B i_{\mathrm{b}}}{m \pi D+B i_{\mathrm{b}}}\right)^{-1}\right]\right) \\
& K_{9}=h_{\mathrm{ext}} \pi c_{0}\left(c_{1}-\frac{c_{0}}{2}\right)\left(\frac{\phi_{0} d}{\lambda_{\mathrm{b}}} \frac{c_{0} \phi_{\mathrm{in}}}{c \phi_{0}}-\frac{1}{B i_{\mathrm{b}}+1} T_{\mathrm{ext}}\right) \\
& +\sum_{m=1}^{\infty}\left(2 \phi_{\mathrm{in}} c \frac{1}{m^{2} \pi^{2}} \sin \left(\frac{m \pi c_{0}}{c}\right)\right. \\
& {\left[\left(-c_{0} \pi \sin \left(\frac{m \pi c_{1}}{c}\right)\left(e^{m \pi D}-1\right)-\frac{\pi h_{\mathrm{ext}}}{\lambda_{\mathrm{b}}} \frac{c}{m \pi}\left(\frac{c}{m \pi}\left(-1+\cos \left(\frac{m \pi c_{0}}{c}\right)\right)+c_{0} \sin \left(\frac{m \pi c_{1}}{c}\right)\right)\right)\right.} \\
& \left(\left(1+e^{2 m \pi D}\right)^{-1}\right) \\
& +\left(-c_{0} \pi \sin \left(\frac{m \pi c_{1}}{c}\right)\left(e^{-m \pi D}-1\right)+\frac{\pi h_{\mathrm{ext}}}{\lambda_{\mathrm{b}}} \frac{c}{m \pi}\left(\frac{c}{m \pi}\left(-1+\cos \left(\frac{m \pi c_{0}}{c}\right)\right)+c_{0} \sin \left(\frac{m \pi c_{1}}{c}\right)\right)\right) \\
& \left.\left.\left(1+e^{-2 m \pi D}\right)^{-1}\right]\right) \\
& K_{10}=h_{\mathrm{ext}} \pi c_{0}\left(c_{1}-\frac{c_{0}}{2}\right)\left(\frac{-\frac{c_{0}+c_{1}}{2 c}+1}{B i_{\mathrm{b}}+1}\right) \\
& -\sum_{m=1}^{\infty}\left(2 \lambda_{\mathrm{b}} \frac{c}{c_{1}-c_{0}} \frac{1}{m^{2} \pi^{2}}\left(\cos \left(\frac{m \pi c_{0}}{c}\right)-\cos \left(\frac{m \pi c_{1}}{c}\right)\right) \frac{\pi h_{\mathrm{ext}}}{\lambda_{\mathrm{b}}} \frac{c}{m \pi}\left(\frac{c}{m \pi}\left(-1+\cos \left(\frac{m \pi c_{0}}{c}\right)\right)+c_{0} \sin \left(\frac{m \pi c_{1}}{c}\right)\right)\right. \\
& \left.\times\left[\left(e^{m \pi D}+e^{-m \pi D} \frac{m \pi D+B i_{\mathrm{b}}}{m \pi D-B i_{\mathrm{b}}}\right)^{-1}+\left(e^{-m \pi D}+e^{+m \pi D} \frac{m \pi D-B i_{\mathrm{b}}}{m \pi D+B i_{\mathrm{b}}}\right)^{-1}\right]\right) \\
& K_{11}=h_{\mathrm{ext}} \pi c_{0}\left(c_{1}-\frac{c_{0}}{2}\right) \frac{c_{0}+c_{1}}{2 c} \frac{1}{B i_{\mathrm{b}}+1} \\
& +\sum_{m=1}^{\infty}\left(2 \lambda_{\mathrm{b}} \frac{c}{c_{1}-c_{0}} \frac{1}{m^{2} \pi^{2}}\left(\cos \left(\frac{m \pi c_{0}}{c}\right)-\cos \left(\frac{m \pi c_{1}}{c}\right)\right) \frac{\pi h_{\mathrm{ext}}}{\lambda_{\mathrm{b}}} \frac{c}{m \pi}\left(\frac{c}{m \pi}\left(-1+\cos \left(\frac{m \pi c_{0}}{c}\right)\right)+c_{0} \sin \left(\frac{m \pi c_{1}}{c}\right)\right)\right. \\
& \left.\times\left[\left(e^{m \pi D}+e^{-m \pi D} \frac{m \pi D+B i_{\mathrm{b}}}{m \pi D-B i_{\mathrm{b}}}\right)^{-1}+\left(e^{-m \pi D}+e^{+m \pi D} \frac{m \pi D-B i_{\mathrm{b}}}{m \pi D+B i_{\mathrm{b}}}\right)^{-1}\right]\right) \\
& -\sum_{m=1}^{\infty}\left(2 \phi_{\mathrm{in}} c \frac{1}{m^{2} \pi^{2}} \sin \left(\frac{m \pi c_{0}}{c}\right) \frac{\pi h_{\mathrm{ext}}}{\lambda_{\mathrm{b}}} \frac{c}{m \pi}\left(\frac{c}{m \pi}\left(-1+\cos \left(\frac{m \pi c_{0}}{c}\right)\right)+c_{0} \sin \left(\frac{m \pi c_{1}}{c}\right)\right)\right. \\
& \left.\times\left[\left(1+e^{2 m \pi D}\right)^{-1}-\left(1+e^{-2 m \pi D}\right)^{-1}\right]\right) \\
& K_{13}=\exp \left(-\frac{\pi\left(L_{\mathrm{c}}-L_{2 \phi}\right)}{\dot{m}_{\mathrm{l}} c_{\mathrm{p}, \mathrm{l}}\left(1 / h_{\mathrm{l}} D_{\mathrm{c}, \mathrm{i}}+1 / h_{\mathrm{sink}} D_{\mathrm{c}, \mathrm{o}}\right)}\right) \exp \left(-\frac{\pi L_{\mathrm{l}}}{\dot{m}_{\mathrm{l}} c_{\mathrm{p}, \mathrm{l}}\left(1 / h_{\mathrm{l}} D_{\mathrm{l}, \mathrm{i}}+1 / h_{\mathrm{ext}} D_{\mathrm{l}, \mathrm{o}}\right)}\right) \\
& K_{14}=\exp \left(-\frac{\pi L_{\mathrm{l}}}{\dot{m}_{\mathrm{l}} c_{\mathrm{p}, \mathrm{l}}\left(1 / h_{\mathrm{l}} D_{\mathrm{l}, \mathrm{i}}+1 / h_{\mathrm{ext}} D_{\mathrm{l}, \mathrm{o}}\right)}\right)\left(1-\exp \left(-\frac{\pi\left(L_{\mathrm{c}}-L_{2 \phi}\right)}{\dot{m}_{\mathrm{l}} c_{\mathrm{p}, \mathrm{l}}\left(1 / h_{\mathrm{l}} D_{\mathrm{c}, \mathrm{i}}+1 / h_{\mathrm{sink}} D_{\mathrm{c}, \mathrm{o}}\right)}\right)\right) T_{\mathrm{sink}} \\
& +\left(1-\exp \left(-\frac{\pi L_{\mathrm{l}}}{\dot{m}_{\mathrm{l}} c_{\mathrm{p}, \mathrm{l}}\left(1 / h_{\mathrm{l}} D_{\mathrm{l}, \mathrm{i}}+1 / h_{\mathrm{ext}} D_{\mathrm{l}, \mathrm{o}}\right)}\right)\right) T_{\mathrm{ext}}
\end{aligned}
$$

\section{Appendix B. Second order equation for the determination of $T_{\mathrm{v}}$}

$$
\begin{aligned}
0= & T_{\mathrm{v}}^{2}\left[c_{\mathrm{p}, 1}\left(1-K_{13}\right)\left(K_{6}\left(K_{1}+K_{2}+K_{7}\right)-\left(K_{4}+K_{5}\right)\left(K_{3}+K_{8}\right)+K_{8} R_{\mathrm{c}} / S_{\mathrm{c}}\left(K_{6}\left(K_{1}+K_{2}\right)-K_{3}\left(K_{4}+K_{5}\right)\right)\right)\right] \\
+ & T_{\mathrm{v}}\left[c_{\mathrm{p}, 1}\left(1-K_{13}\right)\left(\left(K_{3}+K_{8}\right) K_{4} \Delta T+\left(K_{3} K_{4}-K_{1} K_{6}\right) K_{8} \Delta T R_{\mathrm{c}} / S_{\mathrm{c}}+K_{6}\left(-K_{1} \Delta T-K_{7} \Delta T+K_{9}-Q_{\mathrm{in}}\right)\right)\right. \\
& \quad+\left(h_{\mathrm{lv}}-c_{\mathrm{p}, 1} K_{14}\right)\left(K_{6}\left(K_{1}+K_{2}+K_{7}+K_{8}\left(K_{1}+K_{2}\right)\right)-\left(K_{4}+K_{5}\right)\left(K_{3}+K_{8}+K_{3} K_{8} R_{\mathrm{c}} / S_{\mathrm{c}}\right)\right) \\
& \left.\quad+h_{\mathrm{lv}}\left(K_{11}\left(K_{1}+K_{2}+K_{7}+K_{3} K_{7} R_{\mathrm{c}} / S_{\mathrm{c}}\right)-\left(K_{3}+K_{8}+K_{3} K_{8} R_{\mathrm{c}} / S_{\mathrm{c}}\right)\left(K_{10}+h_{\mathrm{ext}} S_{\mathrm{r}}\right)\right)\right] \\
& +c_{\mathrm{p}, 1} K_{14}\left(K_{6}\left(Q_{\mathrm{in}}-K_{9}\right)+\Delta T\left(K_{6}\left(K_{1}+K_{7}+K_{1} K_{8} R_{\mathrm{c}} / S_{\mathrm{c}}\right)-K_{4}\left(K_{3}+K_{8}+K_{3} K_{8} R_{\mathrm{c}} / S_{\mathrm{c}}\right)\right)\right)
\end{aligned}
$$


$+h_{\mathrm{lv}} \Delta T\left(\left(K_{3}+K_{8}\right)\left(K_{4}+K_{10}\right)-\left(K_{6}+K_{11}\right)\left(K_{1}+K_{7}\right)+K_{3} K_{8}\left(K_{4}+K_{10}\right) R_{\mathrm{c}} / S_{\mathrm{c}}-\left(K_{3} K_{7} K_{11}+K_{1} K_{6} K_{8}\right) R_{\mathrm{c}} / S_{\mathrm{c}}\right)$

$+h_{\mathrm{lv}}\left(\left(K_{3}+K_{8}+K_{3} K_{8} R_{\mathrm{c}} / S_{\mathrm{c}}\right)\left(Q_{\mathrm{in}}-K_{12}+h_{\mathrm{ext}} S_{\mathrm{r}}\left(\Delta T+T_{\mathrm{ext}}\right)\right)-\left(K_{6}+K_{11}+K_{3} K_{11} R_{\mathrm{c}} / S_{\mathrm{c}}\right)\left(Q_{\mathrm{in}}-K_{9}\right)\right)$ 